\title{
Graphene nanoclusters embedded nickel cobaltite nanofibers as multifunctional electrocatalyst for glucose sensing and water-splitting applications
}

\author{
Kumar, B. Sachin; Gudla, Visweswara C.; Ambat, Rajan; Kalpathy, Sreeram K.; Anandhan, S.
}

Published in:

Ceramics International

Link to article, DOI:

10.1016/j.ceramint.2019.03.155

Publication date:

2019

Document Version

Peer reviewed version

Link back to DTU Orbit

Citation (APA):

Kumar, B. S., Gudla, V. C., Ambat, R., Kalpathy, S. K., \& Anandhan, S. (2019). Graphene nanoclusters embedded nickel cobaltite nanofibers as multifunctional electrocatalyst for glucose sensing and water-splitting applications. Ceramics International, 45(18, Part B), 25078-25091.

https://doi.org/10.1016/j.ceramint.2019.03.155

\section{General rights}

Copyright and moral rights for the publications made accessible in the public portal are retained by the authors and/or other copyright owners and it is a condition of accessing publications that users recognise and abide by the legal requirements associated with these rights.

- Users may download and print one copy of any publication from the public portal for the purpose of private study or research.

- You may not further distribute the material or use it for any profit-making activity or commercial gain

- You may freely distribute the URL identifying the publication in the public portal 


\section{Graphene Nanoclusters Embedded Nickel Cobaltite Nanofibers as Multifunctional Electrocatalyst for Glucose Sensing and Water- splitting Applications}

B. Sachin Kumar' ${ }^{1}$, Visweswara C. Gudla ${ }^{2}$, Rajan Ambat ${ }^{2}$, Sreeram K. Kalpathy ${ }^{3}$, S. Anandhan ${ }^{1 *}$

${ }^{1}$ Department of Metallurgical and Materials Engineering, National Institute of Technology Karnataka, Mangalore 575025, India.

${ }^{2}$ Section of Materials and Surface Technology, Department of Mechanical Engineering, Technical University of Denmark, Produktionstorvet, DK-2800 Kgs. Lyngby, Denmark.

${ }^{3}$ Department of Metallurgical and Materials Engineering, Indian Institute of Technology Madras, Chennai 600036, India.

*Corresponding author, email id: anandtmg@gmail.com

Phone number: +91-824-2473762 (Office)

Electronic Supplementary Information (ESI) available 


\begin{abstract}
Nickel cobaltite (NCO) attains the apex of Sabatier-type volcano plot for electrochemical reaction compared to simple oxides due to synergetic effect of mixed transition metal cations. The combination of high surface area, aspect ratio, and porosity of electrospun NCO nanofibers (NCO-NF) enhance their electrocatalytic performance by improved electron mobility and more active sites. In the present study, NCO-NF fabricated using poly(styrene-co-acrylonitrile) (SAN) as a sacrificial polymer, were embellished with graphene nanoclusters (GNC), which augment the electrocatalytic performance of the NCONF. The in situ formed GNC along the NCO-NF are result of the interaction between the polar functional groups of the polymer, and the cations of precursor salts during the calcination of precursor nanofibers. The GNC/NCO-NF with least crystallite size and high aspect ratio having porous NCO nanoparticles and in situ grown GNC were developed using sol-gel electrospinning process assisted by calcination of precursor nanofibers. This simple, eco-friendly, and economical synthesis route with unique structure chemistry of SAN to form GNC and the presence of dual cations ( $\mathrm{Ni}$ and $\mathrm{Co}$ ) provides enhanced performance and multifunctionality to GNC/NCO-NF electrodes for electrocatalytic applications, such as biosensors and water-splitting. In the present study, the modified electrodes (GNC/NCO$\mathrm{NF}$ /graphite electrode) exhibited excellent non-enzymatic glucose detection over a wide range of concentration with a lower limit of $1.2 \mu \mathrm{M}$ and sensitivity of $1827.5 \mu \mathrm{A} \cdot \mathrm{mM}^{-1} \cdot \mathrm{mg}^{-1}$ in $0.1 \mathrm{M} \mathrm{NaOH}$. Further, the modified electrodes were also tuned for $\mathrm{H}_{2} \mathrm{O}_{2}$ detection to aid enzymatic glucose sensing. When examined for bifunctional water-splitting in $1 \mathrm{M} \mathrm{NaOH}$, the electrode reached an onset potential of $-0.537 \mathrm{~V}$ and $0.735 \mathrm{~V}$ against reversible hydrogen reference electrode and a Tafel slope of $37.6 \mathrm{mV} \cdot \mathrm{dec}^{-1}$ and $67.0 \mathrm{mV} \cdot \mathrm{dec}^{-1}$ for hydrogen and oxygen evolution reactions, respectively. The results prove that GNC/NCO-NF are promising candidates as multifunctional electrocatalyst.
\end{abstract}

Keywords: Electrospinning; $\mathrm{NiCo}_{2} \mathrm{O}_{4}$; graphene; sensor; electrocatalyst. 


\section{Highlights}

1. Graphene nanocluster/ $\mathrm{NiCo}_{2} \mathrm{O}_{4}(\mathrm{GNC} / \mathrm{NCO})$ nanofibers exhibits multifunctional electrocatalytic behaviour.

2. Lower limit of glucose detection and sensitivity: $1.2 \mu \mathrm{M}$ and $1827.5 \mu \mathrm{A} \cdot \mathrm{mM}^{-1} \cdot \mathrm{mg}^{-1}$.

3. Response time for glucose and $\mathrm{H}_{2} \mathrm{O}_{2}$ sensing is 6 and $1.6 \mathrm{~s}$, respectively.

4. Tafel slopes for hydrogen and oxygen evolution reaction: 37.6 and $67.0 \mathrm{mV} \cdot \mathrm{dec}^{-1}$.

\section{Graphical abstract}

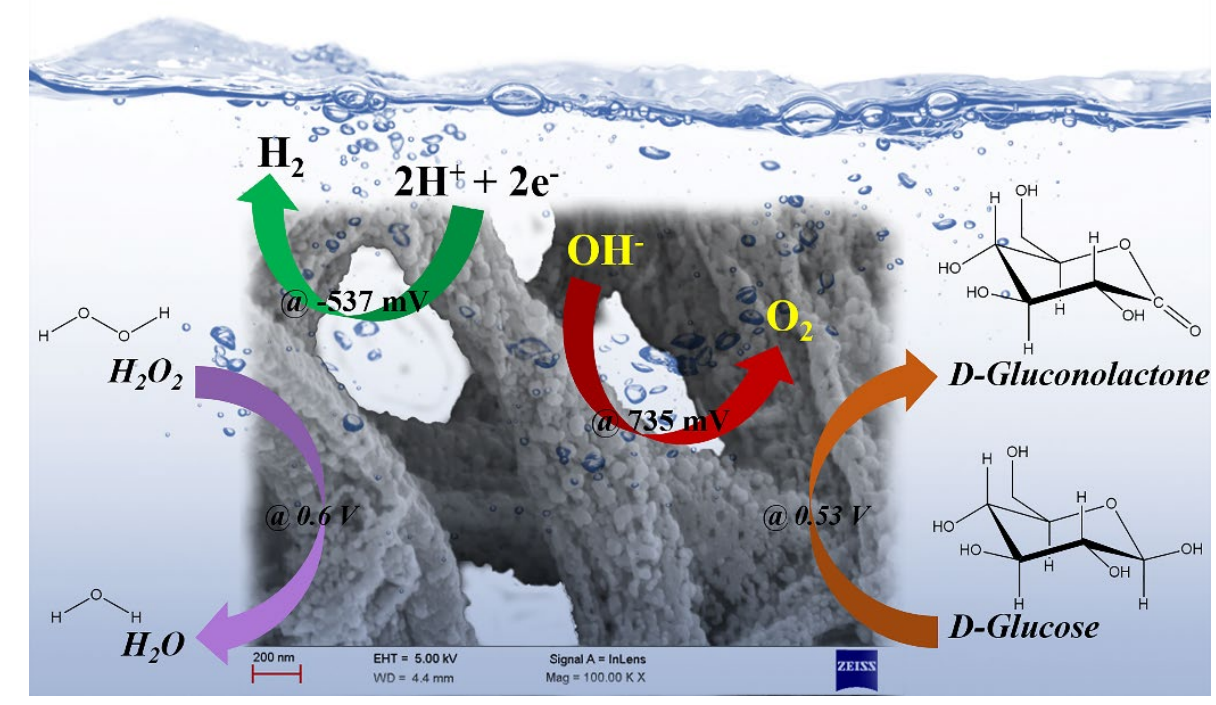




\section{Introduction}

Transition metal oxide nanofibers are promising candidate materials for electrocatalysis given the earth crustal abundance of these metals as well as the size benefits associated with nanofibers. The high aspect ratio and high specific surface area of nanofibers enables efficient charge transportation, which especially makes them attractive for electrocatalytic applications such as biosensors [1] and energy harvesting devices [2,3]. For example, simple transition metal oxide nanofibers like $\mathrm{Co}_{3} \mathrm{O}_{4}, \mathrm{CuO}, \mathrm{NiO}, \mathrm{TiO}_{2}$ have shown immense potential for non-enzymatic glucose sensing [1], which boosts the health industry through improved management of diabetes [4-6]. Another emerging area of their application is in electrocatalytic water splitting for hydrogen production [7], due to the increasing need for renewable energy technologies. A variety of techniques have also evolved over the last decade, which facilitate the easy synthesis and fabrication of transition metal oxide nanofibers [8,9]. All these factors motivate studies for developing transition metal oxide nanofibers with enhanced catalytic and sensing properties as well as to improve our understanding of the underlying mechanisms.

Among transition metal oxides, nickel cobaltite $\left(\mathrm{NiCO}_{2} \mathrm{O}_{4}\right)$ has seized the field of supercapacitors [10], biosensors [11] and electrocatalysis [12]; due to its remarkable oxidation states and better electrical conductivity than simpler oxides like $\mathrm{NiO}$ or $\mathrm{CoO}_{\mathrm{x}}[13]$. Extensive studies on glucose detection and water oxidation have been reported in literature using $\mathrm{NiCo}_{2} \mathrm{O}_{4}(\mathrm{NCO})$ in the form of various nanostructures $[11,14,15]$, hybrid composites [16-18] and carbon-based composite materials [19,20]. Previously, electrospun NiO and $\mathrm{Co}_{3} \mathrm{O}_{4}$ nanofibers have been explored for use in biosensors for glucose monitoring [21,22] and as cells for electrocatalysis [23]. It was soon realized that NCO exhibits superior performance due to its high electronic conductivity and presence of plenty of active sites. NCO has spinel structure, where octahedral cations are easily accessed by electrolyte at the interface [11,24]. Apart from these, graphene-based materials have been explored in depth for various electroanalytical methods [25]. Hence, NCO has been extensively investigated in the presence of graphene derived materials, and their combination showed an excellent electrocatalytic performance towards glucose sensing and oxygen reduction reaction than NCO alone due to the synergistic effect of heterostructures [19,20,26,27]. Another important aspect of glucose sensing is that the oxidation of glucose is always associated with the production of $\mathrm{H}_{2} \mathrm{O}_{2}$. Hence the first-generation glucose sensors were based on $\mathrm{H}_{2} \mathrm{O}_{2}$ 
detection. Given this, it is important that studies involving electrocatalytic and glucose sensing properties of NCO be also conducted in presence of added $\mathrm{H}_{2} \mathrm{O}_{2}$. Furthermore, the enzymatic glucose detection is always associated with the $\mathrm{H}_{2} \mathrm{O}_{2}$ liberation and sensing [28]. In addition, electrocatalytic $\mathrm{H}_{2} \mathrm{O}_{2}$ detection has been major focus in biological, pharmaceutical, food, and textile manufacturing applications [5]. Therefore, $\mathrm{H}_{2} \mathrm{O}_{2}$ detection is an essential aspect of biosensing applications, along with glucose sensing, and in the process, it is also important to avoid interference from other organic and inorganic moieties present with glucose. Some of these species are ascorbic acid, lactic acid, uric acid, dopamine, tryptophane, glycocoll, L-valine, L-proline, L-lysine, sucrose, fructose, maltose, carragene, $\mathrm{NaCl}$, and cations $\left(\mathrm{K}^{+}, \mathrm{Na}^{+}, \mathrm{Ca}^{2+}, \mathrm{Mg}^{2+}, \mathrm{Zn}^{2+}\right)[11,13,14,17,28-33]$.

The focus of the present work was to study the electrocatalytic behaviour of NCO nanofibers (NCO-NF) synthesized by sol-gel assisted electrospinning in which styrene acrylonitrile copolymer (SAN) was used as a binder and viscosity modifier. This process led to the formation of NCO-NF decorated with in-situ graphene nanocluster (GNC), which is novel using SAN as a result of cyclisation and graphitisation of randomly situated functional groups (styrene and nitrile) of SAN in the presence of $\mathrm{Ni}$ and Co compounds. The presence of functional groups in $\mathrm{SAN}$ and the interaction of $\mathrm{Ni} / \mathrm{Co}$ cations with these functional groups helps in formation of GNC material along the NCO-NF (Figure S1). This in-situ grown GNC are more entrenched and bridged with NCO particles as they grow along with the NCO particles. Therefore, they are attributed with better inter-particle interactions as well as particle-electrolyte interaction than when graphene derivates are added separately to NCO nanoparticles for electrocatalytic reactions [34]. Apart from this, the NCO nanoparticles are decorated along the mesoporous nanofibers that enhances their charge transportation efficiency, as well as increases the surface area available for electrocatalytic reactions. This unique in-situ technique for GNCs using SAN as a polymeric binder in sol-gel electrospinning assisted by calcination of precursor nanofibers, provides a simple, ecofriendly, and economical synthesis route to develop an NCO-NF or NCO-NF composites (with or without organic or inorganic materials as fillers) with better morphological, physicochemical, and electrocatalytic properties. And, the GNC/NCO which was developed with this synthesis technique has an enhanced or comparable performance than other Ni or Co or NCO based electrocatalyst in literature. Given these unique advantages, the electrocatalytic performance of this GNC/NCO was characterized by using it as an electrocatalyst in three different reactions: glucose detection, $\mathrm{H}_{2} \mathrm{O}_{2}$ detection, and water electrolysis. 


\section{Materials and methods}

$D$-glucose and sodium hydroxide $(\mathrm{NaOH}$, pellets) were procured from Nice Chemicals, Mumbai, India. Hydrogen peroxide $\left(\mathrm{H}_{2} \mathrm{O}_{2}, 30 \% \mathrm{w} / \mathrm{v}\right)$ was bought from Spectrum Reagents and Chemicals Private Limited, Mumbai, India. The poly(vinylidene fluoride) (PVDF, Solef ${ }^{\circledR}$ 1015, Solvay, Italy) polymer of wt average molecular weight of 575,000 was purchased from Prakash Chemicals Private Limited, Gujarat, India. N, N-dimethylformamide (DMF) was obtained from Sisco Research Laboratories Private Limited, Taloja, Maharashtra, India. All chemicals were of assay $>99 \%$ and were used without further purification.

GNC/NCO-NF were synthesised by sol-gel assisted electrospinning process, followed by calcination of electrospun precursor nanofibers at three different calcination soaking times, $t$ (i.e. 2, 4, and $6 \mathrm{~h}$ ) and temperature of $500^{\circ} \mathrm{C}$ (optimal for NCO growth). Hereafter, the GNC/NCO-NF synthesised using calcination soaking time of 2, 4, and $6 \mathrm{~h}$ will be mentioned as NCO-2, NCO-4, and NCO-6, respectively. The detailed synthesis and characterization techniques of GNC/NCO-NF were explained in our earlier work [34]. The nanostructure morphology and selected area diffraction pattern of polycrystalline GNC/NCO samples were studied using high-resolution transmission microscope (HRTEM, JEM 2100, JEOL, USA). X-ray diffraction (XRD) patterns were recorded to study the phase purity and crystallinity of GNC/NCO-NF, using x-ray diffractometer (DXGE-2P, JEOL, Japan) with monochromatic $\mathrm{Cu} \mathrm{K}_{\alpha}$ radiation $(\lambda=0.154 \mathrm{~nm})$.

The non-crystalline phase, electronic and structural features of GNC/NCO-NF such as band gap energies, defects, and elemental composition were analysed using diffuse reflectance UV-vis-NIR spectrometer (3600+, Hitachi, Japan), photoluminescence (PL) emission spectrometer (Fluoromax-4 Spectrofluorometer, Horiba, France) and x-ray photoelectron spectrometer (XPS, K-Alpha, Thermo Scientific, USA). The absorption spectra of samples were acquired in the wavenumber range of $5-50 \mathrm{kcm}^{-1}$, and the emission spectra were obtained in the wavenumber range of $17-28 \mathrm{kcm}^{-1}$ utilizing an excitation source of 325 $\mathrm{nm}$ wavelength. Determination of oxidation states of the constituent elements and the depth profiling of GNC/NCO-NF were done using XPS, deploying a monochromatic $\mathrm{Al} \mathrm{K}_{\alpha}$ radiation $(1486.6 \mathrm{eV})$. $\mathrm{The}^{\mathrm{Ar}^{+}}$ion beam etching was performed for $25 \mathrm{~s}$ to attain a new surface at each depth. 
All electrocatalytic studies were carried out using an electrochemical workstation (SP150, Bio-Logic Science Instruments, France) with three electrode configuration and test setup as shown in Figure 1 at an ambient environment. The electrolyte and analyte solutions were prepared with Millipore water $(18.2 \mathrm{M} \Omega \cdot \mathrm{cm}$ resistivity), which was purged with nitrogen gas for $20 \mathrm{~min}$ to remove the dissolved oxygen in the solution prior to experiment. The modified cylindrical graphite electrode (GE) with $1 \mathrm{~cm}$ diameter served as the working electrode, whereas saturated calomel electrode (SCE) was used as a reference and platinized platinum as a counter electrode. The GE ends was polished to glassy surface and the walls were insulated with Teflon tape. The polished ends were cleaned by ultrasonication with Millipore water for 30 minutes and air dried. One end of the polished surface was used for electrical connections using soldering and insulation, and the other end was loaded with the catalyst ink.

The catalyst ink was prepared by sonicating $10 \mathrm{mg}$ GNC/NCO-NF in $1 \mathrm{~mL}$ of ethanol. For sensing studies, $40 \mu \mathrm{L}$ of this suspension was loaded on the polished surface of GE and air dried for $10 \mathrm{~min}$, while $1 \mathrm{~mL}$ of the catalyst ink was dropped on the polished surface of GE for hydrogen evolution reaction (HER) or oxygen evolution reaction (OER) studies. After the deposit dried, $10 \mu \mathrm{L}$ of $0.5 \%$ solution of PVDF in DMF was dropped on the deposit to keep the GNC/NCO-NF deposit intact on the electrode. The same amount of PVDF/DMF solution alone was loaded on the polished surface of GE to account as bare electrode. The electrode was dried in air for $6 \mathrm{~h}$ to ensure that any residual solvents were removed. The electrodes where submerged in $0.1 \mathrm{M} \mathrm{NaOH}$ electrolyte for electrocatalytic sensing application and open-circuit potential was applied for one hour to attain equilibrium before each sensing study. $\mathrm{NaOH}(1 \mathrm{M})$ was used as an electrolyte and similar steady state open-circuit potential test was acquired for water-splitting experiments. The electrolyte was continuously stirred at $100 \mathrm{rpm}$ during all electrocatalytic measurements to ensure homogeneity of analyte in electrolyte during sensing, and to avoid the bubbles/gas accumulation on the electrode surface in HER or OER studies. Cyclic voltammetry (CV), Linear sweep voltammetry (LSV), Chronoamperometry (CA), Electrochemical impedance spectroscopy (EIS), and Chronopotentiometry (CP) responses were acquired to study the electrocatalytic behaviour of GNC/NCO-NF. 


\section{Results and discussion}

\subsection{Morphology and crystallinity}

Figure 2a-c shows an HRTEM image of NCO nanoparticles deposited on GNC. The evolution of $\mathrm{NCO}$ and GNCs during calcination of precursor nanofibers is explained in detail elsewhere [34]. In addition to HRTEM images, the confirmation of GNCs were further confirmed using XPS, UV-vis-NIR, PL in our previous study [34]. The GNC structure seems to decrease and diminish with increase in calcination soaking time due to thermal degradation. A thick layered structure was observed for NCO-2, which transforms to almost single layer for NCO-4 and slowly, diminishes for NCO-6. This suggests that the NCO-4 consists of less agglomerated and well-bridged GNC in between the NCO nanoparticles that in turn, improves the electrical/ionic conductivity of the NCO-4 nanofibers. Furthermore, the increased porous structure in NCO nanofibers would predominantly reinforce the surface efficiency and improve the diffusion kinetics of electrolytes into the NCO samples, during electrocatalytic reactions. It can be seen from Figure $2 \mathrm{a}-\mathrm{c}$, that the porosity of NCO-4 is moderately higher than that of NCO-2 and NCO-6, where the particles are loosely packed with interparticle voids (Figure 2a-f). This is attributed to the crystallite splitting phenomenon as confirmed by XRD crystallite analysis and porosity analysis (from Ref. [34]), which provides a larger surface area for the catalyst to improve its catalytic performance.

A well-resolved lattice fringes of corresponding diffraction crystal planes, with respective $d$-spacing of NCO, for all three samples are shown in Figure 2d-f. The SAED patterns of the polycrystalline GNC/NCO samples are seen in Figure 2g-i, which were indexed to the XRD planes of diffraction which correspond to NCO. The inset Figure 2g-i, shows XRD patterns obtained for the samples at different $t$, and the diffraction peaks were indexed to the reflection planes of the reference spinel NCO of The International Centre for Diffraction Data (ICDD) file no. 01-073-1702. No XRD peaks or SAED patterns were observed for GNC and this implies that the structure is non-crystalline, which is in good agreement with the Raman spectroscopy from our previous study [34]. The average crystallite sizes of NCO crystallites calculated for all the three GNC/NCO samples were in the range of $14-17 \mathrm{~nm}$, and a lower one was for NCO-4 due to crystallite splitting phenomena (thermodynamically driven mechanism or mechanical rupture of crystallite splitting within the particle in the presence of crystal splitting or defects or foreign materials such as doped elements, graphene, etc. during the crystallite growth) [34]. It must be noted 
that apart from point defects, dislocations in the crystallite act as active sites for electrochemical reactions.

The dislocation density $\left(\rho_{D}\right)$ is defined as the length of dislocation lines per unit surface of the crystal and is given by $\rho_{D}=\tau / D^{2}$, where $\tau$ is a factor, which is equal to unity for minimum dislocation density [35]. Using the average crystallite sizes ( $D$ ) of NCO-NF as obtained from XRD analysis in Ref.[34], the dislocation densities $\left(\rho_{D}\right)$ in NCO crystallites were estimated to be $3.82 \times 10^{11}, 4.82 \times 10^{11}$, and $3.58 \times 10^{11}$ lines $\cdot \mathrm{cm}^{-2}$ for NCO-2, NCO-4, and NCO-6, respectively. Another method of estimating $\rho_{D}$ in NCO crystallites on basis of XRD analysis for close-packed cubic system was implemented using Ref.[36] \& [37] (Section S2, ESI) and found to be $1.74 \times 10^{11}, 2.19 \times 10^{11}$, and $1.63 \times 10^{11}$ lines $\cdot \mathrm{cm}^{-2}$. It has to be noted that $D$ is a function of lattice strain, lattice parameter, and other assumed factors as explained in Section S2, ESI. From both methods, the $\rho_{D}$ is the highest for NCO-4, which influences the electrochemical reactions, because the charge-transfer resistance decreases with increase in $\rho_{D}$ [38]. This suggests that NCO-4 will have a better electrocatalytic activity.

\subsection{Structural defects and non-crystallinity}

XPS surface analysis was conducted on all the GNC/NCO samples to analyse their catalytic effect. The elemental composition of all the samples were similar as seen from the investigation of earlier work [34]. Further, in this study, a depth analysis of NCO-4 was done to avoid the atmospheric contamination and surface defects. XPS survey spectrum of NCO-4 (Figure S2, ESI) shows the peaks corresponding to Ni Co $2 \mathrm{p}, \mathrm{Co}, \mathrm{O}$, and $\mathrm{C}$ for NCO-4 at

surface and two depths (S, T, and $\mathrm{U}$ stands for surface, depth obtained after $25 \mathrm{~s}$ of $\mathrm{Ar}^{+}$ion etching, and depth obtained after $50 \mathrm{~s}$ of $\mathrm{Ar}^{+}$ion etching, respectively). The $\mathrm{Ni} 2 p$ highresolution spectrum in Figure $3 \mathrm{a}-\mathrm{c}$ conforms to the doublet spin-orbit of $2 p_{3 / 2}(\mathrm{ca} .853 \mathrm{eV})$ and $2 p_{1 / 2}(\mathrm{ca} .871 \mathrm{eV}$ ) electronic configuration with corresponding shake-up satellite peaks denoted as sat. Each of the above peaks have been deconvoluted to the characteristic peaks of $\mathrm{Ni}^{2+}$ and $\mathrm{Ni}^{3+}[11,16]$.

Similarly, Co doublet electronic configurations were conformed at binding energies of ca. $779 \mathrm{eV}$ and $794 \mathrm{eV}$ for $2 p_{3 / 2}$ and $2 p_{1 / 2}$, respectively. Furthermore, the deconvolution of Co $2 p$ high-resolution spectrum showed the characteristic of peaks assigned to $\mathrm{Co}^{2+}$ and $\mathrm{Co}^{3+}$ 
along with its respective shake-up satellite peaks (sat, Figure 3d-f) [11,13]. These results are in line with the early literature and confirmed that both trivalent and divalent cations are well distributed on the surface and coactive to contribute to electrocatalytic reactions. The trivalent cations are expected to aid in the electrochemical process by fast charge transportation across the electrode-electrolyte interface [13]. Also, the ample intrinsic redox couples of cations $\left(\mathrm{M}^{2+} / \mathrm{M}^{3+}\right)$ well distributed in mesoporous NCO nanoparticles could enhance the electroactive sites for catalysis reactions [11].

Figure $3 \mathrm{~g}-\mathrm{i}$ shows the $\mathrm{O} 1 \mathrm{~s}$ high-resolution spectrum at $\mathrm{S}, \mathrm{T}$, and $\mathrm{U}$ of NCO-4 sample. The deconvoluted peaks reveal the presence of inverse spinel lattice oxygen (cation replacements from parent position due oxygen vacancies) [39] and $\mathrm{C}=\mathrm{O}$ functional groups around binding energies of ca. $528 \mathrm{eV}$ and ca. $530 \mathrm{eV}$, accordingly [13]. The peak at ca. 532 $\mathrm{eV}$ can be attributed to the sorbed oxygen moieties on the surface of NCO-4. Furthermore, in Figure $3 \mathrm{j}-1$ of $\mathrm{C} 1 s$ high-resolution spectrum, the deconvoluted peak at ca. $284 \mathrm{eV}$ was ascribed to $\mathrm{C}=\mathrm{C} / \mathrm{C}-\mathrm{C}$ of graphene. The peaks between $285-290 \mathrm{eV}$ belong to the oxygenated carbon species such as $\mathrm{C}=\mathrm{O}$ and $\mathrm{C}-\mathrm{O}$, which are attributed to defects in GNCs (surface or edge) due to oxidation during the synthesis process $[13,34,40]$. All the carbon-based peaks are ascribed to GNCs and oxidized GNCs, which are in good agreement with optical spectroscopies results (Section S4, ESI) and our previous study [34]. Henceforth, achieving the in-situ formed GNCs due to the synergetic presence of functional groups of SAN polymer and cations. It has to be noted that even though GNC/NCO were synthesised at controlled calcination conditions (Section 2), the growth of GNCs are non-homogenous in NCO-NF as the SAN is a random co-polymer and the growth of GNCs is expected only at the blocks of nitrile functional groups in the SAN [41]. This suggests that SAN is an potential and efficient polymeric binder to develop GNC/metal-oxide nanofibers from sol-gel electrospinning process assisted by calcination.

Additional peaks arise around binding energies of $280 \mathrm{eV}$ and $292 \mathrm{eV}$ in Figure 3k and 31 as the sample is etched along the depth of the NCO-NF, which correspond to C-O-M i.e. metal oxide/C interface (reason for GNC formation in presence of cations) [42] and characteristic shake-up satellite of graphene [40], respectively. This suggests that the GNCs are grown as template/substrate structures in between the NCO nanoparticles, which enhance the electrocatalytic performance of NCO-NF. Further, the supplementary peaks in Figure 31 around $295 \mathrm{eV}$ and $297 \mathrm{eV}$ are due to oxidation of carbon-based material $\left(\mathrm{CO}_{2}\right.$ formed are 
adsorbed on cations) [43] and surface charging [44], respectively, as a result of $\mathrm{Ar}^{+}$ion etching during XPS analysis. The presence of GNC boosts up the electrocatalytic activity due to the presence of large surface area, active (defective) sites (by physic or chemisorption), and enhanced electrical/ionic conductivity [13,26,32]. Hence, the GNC/NCO composite nanofibers were expected to be suitable for the electrocatalytic process with significantly improved sensitivity in detection of analytes.

\subsection{Electrocatalytic sensing behaviour of NCO-NF}

Figure 4a shows typical CV curves acquired for the bare GE and GNC/NCO/GE under the applied potential from 0 to $0.7 \mathrm{~V}$ in $0.1 \mathrm{M} \mathrm{NaOH}$ electrolyte in presence of $1 \mathrm{mM}$ glucose. For NCO-4 with $1 \mathrm{mM}$ glucose, two pairs of anodic peaks at ca. $0.32 \mathrm{~V}$ (labelled A) and 0.48 $\mathrm{V}$ (labelled B), as well as cathodic peaks at ca. $0.20 \mathrm{~V}$ (labelled C) and $0.40 \mathrm{~V}$ (labelled D) were observed which can be ascribed to the reversible redox reactions of $\mathrm{Ni}^{2+} / \mathrm{Ni}^{3+}$ and $\mathrm{Co}^{2+} / \mathrm{Co}^{3+}[14,21]$. On the contrary, no redox peaks were found for bare GE in the presence or absence of glucose (Figure 4) as no such redox reactions occur. The redox reactions of NCO in basic alkaline electrolyte are [29]:

$$
\begin{gathered}
\mathrm{NiCO}_{2} \mathrm{O}_{4}+\mathrm{OH}^{-}+\mathrm{H}_{2} \mathrm{O} \stackrel{0.1 \mathrm{NaOH}}{\longleftrightarrow} \mathrm{NiOOH}+2 \mathrm{CoOOH}+e^{-} \\
\mathrm{CoOOH}+\mathrm{OH}^{-} \stackrel{0.1 \mathrm{MaOH}}{\longleftrightarrow} \mathrm{COO}_{2}+\mathrm{H}_{2} \mathrm{O}+e^{-}
\end{gathered}
$$

Among the three NCO/GE samples, the area enclosed by the CV curves is the largest for NCO-4/GE, which suggests that NCO-4 has higher electrocatalytic activity than the other samples. This may be explained through a combination of several factors such as the greater surface area arising from the more porous structure, enhanced active sites obtained by crystalline splitting [14,34], multiple band gaps, and the less agglomerated GNC [26]. Besides, it has been reported in literature that the electrocatalytic activity of NCO increases in the presence of $\mathrm{NiO}$. This is partly due to the increased surface cation concentration. Additionally, $\mathrm{Ni}^{2+} \rightarrow \mathrm{Ni}^{3+}$ oxidation occurs at more negative potential than $\mathrm{Co}^{3+} \rightarrow \mathrm{Co}^{4+}$ [24], which is responsible for sensing behaviour. A closely related phenomena is the transformation of inverse spinel to normal spinel with increase in calcination soaking time [45], Essentially, the Ni cations meet the electrolyte at the surface of the material as they move from tetrahedral to octahedral voids in the crystal structure and facilitates fast electron transfer across the interface $[13,29]$. However, maintaining an optimal soaking time is also 
necessary as the particle shape needs to be retained. Along similar reasoning, one may expect that NCO-4 would manifest better electrocatalytic performance.

The CVs corresponding to NCO-4/GE at different concentrations of glucose are shown in Figure $4 \mathrm{~b}$ in the applied potential range of 0-0.8 V. It is clear that the NCO-4/GE exhibits a significant increase in the anodic peak current after the addition of glucose, which suggests better electrocatalytic activity of NCO-4 nanofibers towards glucose oxidation. The electrocatalytic mechanism of the GNC/NCO exposed to glucose in alkaline electrolyte can be described by the following equations $[14,33]$ :

$$
\begin{gathered}
\mathrm{Ni}^{2+}+\mathrm{Co}^{2+} \stackrel{0.1 \mathrm{M} \mathrm{NaOH}}{\longrightarrow} \mathrm{Ni}^{3+}+\mathrm{Co}^{3+}+2 e^{-} \\
\mathrm{NiOOH}+2 \mathrm{CoOOH}+\mathrm{C}_{6} \mathrm{H}_{12} \mathrm{O}_{6} \stackrel{0.1 \mathrm{M} \mathrm{NaOH}}{\longrightarrow} \mathrm{NiCo}_{2} \mathrm{O}_{4}+\mathrm{C}_{6} \mathrm{H}_{10} \mathrm{O}_{6}+2 \mathrm{H}_{2} \mathrm{O}+2 e^{-}
\end{gathered}
$$

First, the $\mathrm{Ni}^{2+}$ and $\mathrm{Co}^{2+}$ cations from $\mathrm{NCO}$ oxidise to $\mathrm{Ni}^{3+}$ and $\mathrm{Co}^{3+}$ species due to the applied voltage by losing two electrons. This is the reason for the higher anodic peak current of NCO/GE compared to bare GE. Then, upon addition of glucose to the electrolyte, glucose oxidises to gluconolactone by transferring two electrons to the electrolyte and thus a further increase in the anodic peak current is observed. The oxidation of cations and glucose occur simultaneously at the same applied voltage, but the rate of oxidation of cations at the surface of the NCO-NF determines the rate of detection of glucose. Nevertheless, it can be concluded that glucose sensing is an intrinsic electrocatalytic property of NCO-NF and it can be tuned by controlling the morphological structure and electronic properties of the material.

The electrocatalytic sensing properties of bare GE and NCO-4/GE were evaluated at various $\mathrm{H}_{2} \mathrm{O}_{2}$ concentrations. Figure $4 \mathrm{c}$ shows the relevant $\mathrm{CV}$ curves. The positive anodic current for NCO-4 without $\mathrm{H}_{2} \mathrm{O}_{2}$ comes from the oxidation of cations, as described in Equation (3). The increase in oxidation current by upon addition of $\mathrm{H}_{2} \mathrm{O}_{2}$ in $\mathrm{NaOH}$ can be attributed to the oxidation of $\mathrm{H}_{2} \mathrm{O}_{2}$ as:

$$
\mathrm{H}_{2} \mathrm{O}_{2}+2 \mathrm{OH}^{-} \stackrel{0.1 \mathrm{MNaOH}}{\longrightarrow} 2 \mathrm{H}_{2} \mathrm{O}+\mathrm{O}_{2}+2 e^{-}
$$

In the $\mathrm{CV}$ curves of NCO-4/GE with $100 \mu \mathrm{M}$ and $400 \mu \mathrm{M} \mathrm{H}_{2} \mathrm{O}_{2}$, the anodic peaks at ca. 0.35 $\mathrm{V}$ and ca. $0.5 \mathrm{~V}$ and the cathodic peaks ca. $0.2 \mathrm{~V}$ and ca. $0.4 \mathrm{~V}$ represent the redox couples of Equations (1) and (2), respectively. The higher anodic peak current with increasing $\mathrm{H}_{2} \mathrm{O}_{2}$ concentration indicates good electrocatalytic activity of GNC/NCO-NF for $\mathrm{H}_{2} \mathrm{O}_{2}$ oxidation. A 
plausible reaction mechanism for $\mathrm{NCO}$ with $\mathrm{H}_{2} \mathrm{O}_{2}$ in alkaline medium has been proposed in literature $[46,47]$ :

$$
\begin{gathered}
2 \mathrm{M}^{2+}+\mathrm{H}_{2} \mathrm{O}_{2} \stackrel{0.1 \mathrm{M} \mathrm{NaOH}}{\longrightarrow} M^{2+} \stackrel{a d s}{\leftrightarrow} \mathrm{OHHO} \stackrel{a d s}{\leftrightarrow} M^{2+} \\
M^{2+} \stackrel{a d s}{\leftrightarrow} \mathrm{OHHO} \stackrel{a d s}{\leftrightarrow} M^{2+} \stackrel{0.1 M \mathrm{NaOH}}{\longrightarrow} M^{3+} \rightarrow \cdot \mathrm{OHHO}^{\bullet} \leftarrow M^{3+} \\
M^{3+} \rightarrow \mathrm{OHHO}^{\bullet} \leftarrow \mathrm{M}^{3+} \stackrel{0.1 \mathrm{MaOH}}{\longrightarrow} 2 \mathrm{M}^{3+}+2 \mathrm{OH}^{-}
\end{gathered}
$$

where $M$ represents both $\mathrm{Ni}$ and Co cations. Essentially, the divalent cations $\left(M^{2+}\right)$ transfer electrons from oxygen atoms of $\mathrm{H}_{2} \mathrm{O}_{2}$ to form a complex species as shown in Equations (6) and (7), which eventually results in the formation of trivalent cations $\left(M^{3+}\right)$. Subsequently, the $\mathrm{O}-\mathrm{O}$ bond elongation and electron distribution takes place, and $\mathrm{OH}^{-}$ions are released to the electrolyte along with oxidation of cations in GNC/NCO-NF.

Figure 5a shows the CV curves of NCO-4/GE at various scan rates (20 to $250 \mathrm{mV} \cdot \mathrm{s}^{-1}$ ) in the presence of $1 \mathrm{mM}$ glucose in $\mathrm{NaOH}$ electrolyte. The anodic and cathodic peak currents increase with increasing scan rate. Both the anodic and cathodic peak currents appear to satisfy a linear fit with the scan rates, as seen from Figure 5b. This demonstrates that electrocatalytic process for glucose detection is kinetically controlled as previously suggested [13].

\subsection{Amperometric detection}

The CA analysis was carried out to estimate the detection limit and sensitivity values of NCO-4/GE in $0.1 \mathrm{M} \mathrm{NaOH}$ electrolyte $\left(\mathrm{pH} 13\right.$ and scan rate $\left.=100 \mathrm{mV} \cdot \mathrm{s}^{-1}\right)$. An optimal steady-state potential for analyte electrocatalytic performance was obtained by performing LSV at a slow scan rate (i.e. $2 \mathrm{mV} \cdot \mathrm{s}^{-1}$ ). These optimal steady-state potentials vs. SCE were found to be $0.53 \mathrm{~V}$ and $0.6 \mathrm{~V}$ for glucose and $\mathrm{H}_{2} \mathrm{O}_{2}$ detection, respectively (Figure S5, ESI).

Figure 6a shows a typical CA response of NCO-4/GE upon successive addition of glucose into constantly stirred electrolyte. The successive addition of glucose concentration was in the range of 50-1100 $\mu \mathrm{M}$. The sensor responded swiftly upon addition of glucose at each step and the steady state current was reached in ca. $6 \mathrm{~s}$ (Figure 6c). Also, the sensor showed a step-like increase in response current with successive addition, which may be attributed to the homogenous electrocatalytic activity and enhanced conductivity obtained in 
NCO-4 nanofibers. Figure $6 \mathrm{~b}$ displays the calibration curve for glucose detection, obtained by measuring the current change with each incremental addition of glucose, and plotting the same against the specific concentration of glucose. As seen in Figure 6b, the response of the sensor shows a linear relationship towards glucose for the concentration of 50-400 $\mu \mathrm{M}$ and $400-1100 \mu \mathrm{M}$ with a correlation coefficient of ca 0.989 and sensitivity values equal to 1827.5 $\mu \mathrm{A} \cdot \mathrm{mM}^{-1} \cdot \mathrm{mg}^{-1}$ and $1072.5 \mu \mathrm{A} \cdot \mathrm{mM}^{-1} \cdot \mathrm{mg}^{-1}$, respectively. The limit of detection (LOD) and limit of quantification (LOQ) of the CA glucose sensor were estimated using Equations (5) and (6) [29]:

$$
\begin{aligned}
& L O D=\left(3 S_{b}\right) / m \\
& L O Q=\left(10 S_{b}\right) / m,
\end{aligned}
$$

where $S_{b}$ is the standard deviation of blank signal for ten measurements $(0.000302 \mathrm{~mA})$ and $\mathrm{m}$ is the slope value extracted from the calibration plot. Thus, the calculated LOD and LOQ for glucose sensor in the linear region of $50-400 \mu \mathrm{M}$ were $1.2 \mu \mathrm{M}$ and $4.1 \mu \mathrm{M}$, respectively.

The typical CA response for NCO-4/GE for an optimal applied voltage of $0.6 \mathrm{~V}$, with successive addition of $\mathrm{H}_{2} \mathrm{O}_{2}(20-700 \mu \mathrm{M})$ is shown in Figure 7a. The sensor response towards $\mathrm{H}_{2} \mathrm{O}_{2}$ was more rapid as compared with that towards glucose, which achieved a steady-state current within ca. $1.6 \mathrm{~s}$ (Figure 7c). This rapid increase in response time indicates exceptional electrocatalytic oxygen evolution reaction performance of $\mathrm{NCO} /$ graphene material [48]. By measuring the change in current for the corresponding addition of $\mathrm{H}_{2} \mathrm{O}_{2}$, a calibration plot was designed akin to that of glucose. Here in Figure 7b, again two regions of linear fits were found for different range of $\mathrm{H}_{2} \mathrm{O}_{2}$ concentration, i.e., 20-200 $\mu \mathrm{M}$ for lower concentration $\left(R^{2}\right.$ $=0.959)$ and $200-700 \mu \mathrm{M}$ for higher concentration of $\mathrm{H}_{2} \mathrm{O}_{2}\left(R^{2}=0.932\right)$. The sensitivity of $\mathrm{H}_{2} \mathrm{O}_{2}$, for these two regions of response were $1322.5 \mu \mathrm{A} \cdot \mathrm{mM}^{-1} \cdot \mathrm{mg}^{-1}$ and $427.3 \mu \mathrm{A} \cdot \mathrm{mM}^{-1} \cdot \mathrm{mg}^{-}$ ${ }^{1}$, subsequently. The LOD and LOQ for $\mathrm{H}_{2} \mathrm{O}_{2}$ sensor was estimated to be $1.7 \mu \mathrm{M}$ and $5.7 \mu \mathrm{M}$, respectively, at the region of lower concentration.

The selectivity of a sensor is a material property, and the literature suggests no significant interference of accompanying species with glucose or $\mathrm{H}_{2} \mathrm{O}_{2}$ detection, when NCO and $\mathrm{NCO} /$ graphene derived electrodes are used. Furthermore, it has been reported that NCO and $\mathrm{NCO}$ /graphene derived electrodes provide excellent selectivity towards analytes in the presence of interferents $[11,13,14,17,28-33]$. The stable and concurrent stepwise response 
recorded during the successive injection of different concentrations of analytes marks the steady electrocatalytic activity. In addition, the absence of hindrance in successive stepwise response of the sensing process suggests the distinguished operational stability and repeatability of the $\mathrm{GNC} / \mathrm{NCO} / \mathrm{GE}$ electrodes.

\subsection{EIS analysis}

The electrical/ionic conductivity and charge-transfer properties of NCO-4/GE electrodes are influential factors of sensor activity. EIS was conducted to evaluate the physicochemical process at the surface of the electrode. The important measurements done in this context relate to the response time variation, charge-transfer capability at high frequency and mass transfer competence at low frequency. The EIS data were analysed using Nyquist plot, which represents the frequency response of electrode/electrolyte interface by examining the imaginary component $\left(-Z^{\prime \prime}\right)$ of the impedance and the real component $\left(Z^{\prime}\right)$. The Nyquist plots of the sensors in the absence and presence of analytes are shown in Figure $8 \mathrm{a}$ and $8 \mathrm{~b}$. It was observed that the Nyquist plot in absence of analyte (Figure S6, ESI) had a less prominent semi-circular region, and a more prominent semicircle with reduced diameter in the presence of glucose. This semicircle diameter describes the charge-transfer resistance ( $R_{c t}$ ) at electrode/electrolyte interface and the substantially reduced diameter therefore suggests enhanced charge conductivity at the electrode/electrolyte interface.

Along similar lines, the diameter of the semicircle was found to be smaller in presence of $\mathrm{H}_{2} \mathrm{O}_{2}$, which again suggests more intensified charge-transfer at the electrode/electrolyte interface. To have an insight into the interface dynamics, a simple Randles equivalent circuit (Figure 8c) was fitted to the Nyquist plots based on Bode phase plots (Figure S7, ESI) assuming defects to be present in the material. The fitted circuit is compatible with the plots, and the parameters obtained are tabulated in Table 1. The low frequency regions of the Nyquist plots are not linear for both the analytes. This confirms that there was no significant mass diffusion process involved at the electrode/electrolyte interface. Hence, $R_{c t}$ (a function of the working electrode potential and the analyte concentration) alone influence the charge-transfer rate (sensing behaviour) at the electrode during the oxidation of analytes without any diffusion impedance contribution [33]. The $R_{\text {elect }}$ corresponds to the electrolyte resistance, $Q_{C P E}$ and $C_{d l}$ represent the constant phase element 
and pseudo capacitance of double-layer. In case of non-ideal capacitance, i.e. material having defects, $Q_{C P E}$ cannot be considered as capacitance and hence, $C_{d l}$ is given by [49]:

$$
C_{d l}=R_{c t}^{(1-a) / a} \times Q_{C P E}^{1 / a}
$$

where $a$ is the exponential factor, which is equal to zero when $Q_{C P E}$ represents pure resistor and unity when $Q_{C P E}$ is pseudo capacitance.

From Table 1, it is observed that $R_{c t}$ and $C_{d l}$ decrease upon the addition of analytes to the electrolyte, which is synchronous with the increase in response current as seen from $\mathrm{CV}$ and CA [33]. The decrease in $C_{d l}$ may be attributed to decrease in defects/active sites during the electrocatalytic reaction. Therefore, $C_{d l}$ is the least for bare GE as no active sites/ionic species present in the vicinity of the electrode. This phenomenon also explains the diffusion of analytes from electrolyte to electrocatalytic active sites. Since $R_{c t}$ is inversely proportional to charge-transfer rate at the electrode, the $\mathrm{CV}$ and $\mathrm{CA}$ analysis shows a decrease in $R_{c t}$ with increase in analyte concentration. This suggests that at a higher concentration of analytes, a better sensing efficiency is possible, and at a step out, it must be noted that the normal glucose level in human blood and urine is in the range of $3.9-10 \mathrm{mM}$ and $0-0.8 \mathrm{mM}$, respectively. Hence, the NCO-4/GE sensor would efficiently perform well in these regions.

Table 2 shows the comparison of glucose or $\mathrm{H}_{2} \mathrm{O}_{2}$ sensing performance of GNC/NCO nanofibers developed in the present work with some previous literature. In general, it can be seen that NCO-4/GE has comparable or better performance parameters than that of other electrocatalyst, filler, electrode, or NCO developed by different synthesis routes, in assessment with response time, linear range, limit of detection or sensitivity. Further, in comparison with those electrocatalyst having far better performance in mentioned parameters, the GNC/NCO nanofibers holds good in terms of simple, less impurities, ecofriendly, and economical synthesis route (compared to multi-stage, template-assisted, solvo/hydrothermal methods, electrodeposition etc.), in-situ GNCs formation that is efficient (compared to dispersion or coating method), and type of electrode substrate used that is feasible (compared to foam, conductive oxide plates or expensive metal foils). 


\subsection{Electrocatalytic water-splitting}

The water-splitting properties of NCO-4 nanofibers are investigated through $\mathrm{CV}$ and $\mathrm{CP}$, and Tafel polarisation studies in $1 \mathrm{M} \mathrm{NaOH}$ electrolyte medium. The steep increase in anodic current beyond $0.6 \mathrm{~V}$ in Figure $4 \mathrm{a}$, corresponds to the oxygen evolution reaction through four-electron transfer process in basic medium,

$$
4 \mathrm{OH}^{-} \rightarrow 2 \mathrm{H}_{2} \mathrm{O}+\mathrm{O}_{2}+4 e^{-}
$$

$\mathrm{CV}$ was carried out with conventional three electrodes set-up for 50 cycles, at an optimal scanning rate of $100 \mathrm{mV} \cdot \mathrm{s}^{-1}$. CV were obtained in the negative potential window of $0.0 \mathrm{~V}$ to 1.6 $\mathrm{V}$ for HER and in the positive potential range of $0 \mathrm{~V}$ to $0.8 \mathrm{~V}$. CP study was employed to study the stability of the electrocatalytic process of HER at a constant current of $-300 \mathrm{~mA}$ and OER at a constant current of $300 \mathrm{~mA}$, for a duration of $1800 \mathrm{~s}$ each.

\subsubsection{Hydrogen evolution reaction}

The CV studies of GNC/NCO-NF were employed for HER analysis as it describes the electrode/ion interaction at the cathode. The $\mathrm{H}^{+}$ion from electrolyte accepts electrons at cathode and becomes a nascent hydrogen atom (chemisorbed) on the electrode surface and is later converted to $\mathrm{H}_{2}$ gas [23]. Also, the electrocatalytic efficiency can be explained by $\mathrm{CV}$ using the response current, as it is a direct indicator of the adsorbed ion concentration. Figure 9a shows the HER CV curve for NCO-4/GE. The onset potential of $H_{2}$ was found to $-0.781 \mathrm{~V}$ (-781 mV vs. SCE) or $-0.914 \mathrm{~V} @ 10 \mathrm{~mA} \cdot \mathrm{cm}^{-2}$ (vs. RHE), beyond which there was a vigorous $\mathrm{H}_{2}$ evolution and a drastic increase in the cathodic current. The present results show that the efficiency of GNC/NCO-NF as electrocatalyst is better than that of $\mathrm{Co}_{3} \mathrm{O}_{4}$ nanofibers prepared by sol-gel electrospinning in an earlier research [23].

The inset in Figure 9a is the CP curve obtained for HER, where at the constant applied current of $-300 \mathrm{~mA}$, a continuous reduction of the $H^{+}$ions take place at the cathode surface and thereby resulting in continuous evolution of $\mathrm{H}_{2}$. The electrode potential attained during $\mathrm{CP}$ analysis at constant current depends on many factors such as, redox couples available in NCO-4, active sites, and $\mathrm{H}^{+}$concentration in electrolyte [50]. The CP result shows continuous evolution of $H_{2}$ for $1800 \mathrm{~s}$ with no significant change in the potential, which implies a promising long-term kinetic stability of GNC/NCO-NF for use in electrocatalytic water-splitting applications. 


\subsubsection{Oxygen evolution reaction}

The OER analysis was done using CV experiments of NCO-4 nanofibers along similar lines as HER, but over a positive potential range (0-0.8 V). From the CV curve of Figure 9b, the onset potential of $\mathrm{O}_{2}$ evolution was noted as $0.491 \mathrm{~V}(491 \mathrm{mV}$ vs. SCE) or $0.855 \mathrm{~V} @ 10$ $\mathrm{mA} \cdot \mathrm{cm}^{-2}$ (vs. RHE). The onset potential is the minimum potential at which the oxygen is formed at the electrode at given conditions. The obtained onset potential of $\mathrm{O}_{2}$ evolution for GNC/NCO (0.735 V vs. reference hydrogen electrode, RHE) was found to be half the value reported for $\mathrm{NCO} /$ reduced graphene oxide electrode (1.57 V vs. RHE) [48] and comparable to $\mathrm{Co}_{3} \mathrm{O}_{4}$ nanofibers [23] fabricated using similar technique. This indicates the superior electrocatalytic activity of GNC/NCO/GE electrodes.

Figure $9 \mathrm{~b}$ shows the results of electrostatic stability studies for OER using $\mathrm{CP}$ at a constant applied current of $+300 \mathrm{~mA}$. A sharp increase in potential was observed before a stable potential range is attained where $\mathrm{OH}^{-}$is oxidised to oxygen. A stable potential is achieved, as the fresh bubbles forming at the electrode is in equilibrium with the escaping ones. The continuous evolution of oxygen for the entire $1800 \mathrm{~s}$ represents better kinetic stability of the electrocatalyst for OER. Furthermore, the onset potential (Table 3) conveys that the electrocatalytic performance of NCO-4 nanofibers is higher towards OER compared to HER due to the affinity of active sites (cations especially in octahedral sites) towards $\mathrm{OH}^{-}$ adsorption at the surface $[23,51]$. The Tafel polarisation plot of NCO-4 obtained by LSV at a scan rate of $5 \mathrm{mV} \cdot \mathrm{s}^{-1}$ is shown in Figure 9c. The Tafel slopes for HER and OER were measured to be $37.6 \mathrm{mV} \cdot \mathrm{dec}^{-1}$ and $67.0 \mathrm{mV} \cdot \mathrm{dec}^{-1}$, respectively. The Tafel slope values are in agreement with the Volmer-Tafel mechanism for HER with the Tafel reaction being the ratelimiting step [12]. Table 3 shows the comparison of water-splitting parameters of GNC/NCO nanofibers with some electrocatalyst in literature. It is observed that GNC/NCO has comparable performance in the literature. However, the electrocatalyst that out perform GNC/NCO nanofibers has a similar limitation as biosensor electrodes due to their complex, additional or expensive synthesis process and electrode substrates.

\section{Summary and conclusions}

The catalytic effect of precursor ions ( $\mathrm{Ni}$ and $\mathrm{Co}$ ) resulted in the formation of in-situ GNC in NCO nanofiber due to the dynamic interaction of cations with functional groups of the SAN polymer. The presence of GNC deep-seated with NCO nanoparticles along the NCO-NF 
were confirmed by HRTEM and XPS depth profile analysis. The porosities, multiple band gap energies, NCO crystal defects and graphene $s p^{2}$ defects favoured significant improvement in the electrocatalytic activity of NCO towards sensing of glucose and watersplitting phenomena. Among the fibres calcined at different soaking times, NCO-4 nanofibers showed better electrocatalytic activity because of the synergistic effects of less agglomeration in the GNC, continuous links between NCO nanoparticles, and increase in defect concentration of NCO nanocrystallite by crystallite splitting

These features of NCO-4 nanofibers resulted in better sensitivity of analytes in NCO4/GE sensors, i.e. $1827.5 \mu \mathrm{A} \cdot \mathrm{mM}^{-1} \cdot \mathrm{mg}^{-1}$ for glucose and $1322.5 \mu \mathrm{A} \cdot \mathrm{mM}^{-1} \cdot \mathrm{mg}^{-1}$ for $\mathrm{H}_{2} \mathrm{O}_{2}$, over a wide linear concentration of 50-400 $\mu \mathrm{M}$ and $20-200 \mu \mathrm{M}$, respectively. The LOD and LOQ of both analytes were in similar range as in earlier literature. The response time for glucose detection was $6 \mathrm{~s}$ and that of $\mathrm{H}_{2} \mathrm{O}_{2}$ was $1.6 \mathrm{~s}$, using $\mathrm{NCO}-4 / \mathrm{GE}$ sensor. The response time, LOD, and LOQ for both the analytes were also comparable to the earlier literature. NCO-4/GE electrodes showed good electrocatalytic water-splitting behaviour with an onset potential of approximately $-0.78 \mathrm{~V}$ (vs. SCE) for hydrogen evolution and around $0.49 \mathrm{~V}$ (vs. SCE) for oxygen evolution in alkaline medium. In summary, NCO-4 nanofibers have a promising potential for multifunctional electrocatalytic activity such as simultaneous glucose detection and water oxidation in alkaline medium.

\section{Funding information}

This research received no specific funding from any funding agency.

\section{Acknowledgements}

B. S. Kumar is grateful for a research fellowship granted by National Institute of Technology Karnataka (NITK), India. The PL spectrometer used in this study was procured through Technical Education Quality Improvement Program (TEQIP-phase II) and the authors acknowledge TEQIP-phase II for the same. The authors are obliged to Dr. S. B. Arya and Dr. T. Baskaran, NITK, India, for their kind assistance in some of the electrochemical studies. 


\section{References}

[1] K. Mondal, A. Sharma, Recent advances in electrospun metal-oxide nanofiber based interfaces for electrochemical biosensing, RSC Adv. 6 (2016) 94595-94616. doi:10.1039/C6RA21477K.

[2] X. Shi, W. Zhou, D. Ma, Q. Ma, D. Bridges, Y. Ma, A. Hu, Electrospinning of Nanofibers and Their Applications for Energy Devices, J. Nanomater. (2015). doi:10.1155/2015/140716.

[3] Y. Liao, T. Fukuda, S. Wang, Electrospun Metal Oxide Nanofibers and Their Energy Applications, (2016). doi:10.5772/63414.

[4] A. Heller, B. Feldman, Electrochemical Glucose Sensors and Their Applications in Diabetes Management, Chem Rev. 108 (2008) 2482-2505. doi:10.1021/cr068069y.

[5] C. Chen, Q. Xie, D. Yang, H. Xiao, Y. Fu, Y. Tan, S. Yao, Recent advances in electrochemical glucose biosensors: a review, RSC Adv. 3 (2013) 4473-4491. doi:10.1039/C2RA22351A.

[6] K. Tian, M. Prestgard, A. Tiwari, A review of recent advances in nonenzymatic glucose sensors, Mater. Sci. Eng. C. 41 (2014) 100-118. doi:10.1016/j.msec.2014.04.013.

[7] X. Li, X. Hao, A. Abudula, G. Guan, Nanostructured catalysts for electrochemical water splitting: current state and prospects, J. Mater. Chem. A. 4 (2016) 11973-12000. doi:10.1039/C6TA02334G.

[8] C. Yuan, H. Bin Wu, Y. Xie, X.W. (David) Lou, Mixed Transition-Metal Oxides: Design, Synthesis, and Energy-Related Applications, Angew Chem Int Ed. 53 (2014) 1488-1504. doi:10.1002/anie.201303971.

[9] T. Guo, M.-S. Yao, Y.-H. Lin, C.-W. Nan, A comprehensive review on synthesis methods for transition-metal oxide nanostructures, CrystEngComm. 17 (2015) 35513585. doi:10.1039/C5CE00034C.

[10] D.P. Dubal, P. Gomez-Romero, B.R. Sankapal, R. Holze, Nickel cobaltite as an emerging material for supercapacitors: An overview, Nano Energy. 11 (2015) 377-399. doi:10.1016/j.nanoen.2014.11.013.

[11] W. Huang, Y. Cao, Y. Chen, J. Peng, X. Lai, J. Tu, Fast synthesis of porous $\mathrm{NiCo}_{2} \mathrm{O}_{4}$ hollow nanospheres for a high-sensitivity non-enzymatic glucose sensor, Appl. Surf. Sci. 396 (2017) 804-811. doi:10.1016/j.apsusc.2016.11.034.

[12] X. Gao, H. Zhang, Q. Li, X. Yu, Z. Hong, X. Zhang, C. Liang, Z. Lin, Hierarchical $\mathrm{NiCo}_{2} \mathrm{O}_{4}$ Hollow Microcuboids as Bifunctional Electrocatalysts for Overall WaterSplitting, Angew Chem Int Ed. 55 (2016) 6290-6294. doi:10.1002/anie.201600525.

[13] B. Wang, Y. Cao, Y. Chen, X. Lai, J. Peng, J. Tu, X. Li, Rapid synthesis of rGO conjugated hierarchical $\mathrm{NiCo}_{2} \mathrm{O}_{4}$ hollow mesoporous nanospheres with enhanced glucose sensitivity, Nanotechnology. 28 (2017) 25501. doi:10.1088/09574484/28/2/025501.

[14] S. Cui, J. Zhang, Y. Ding, S. Gu, P. Hu, Z. Hu, Rectangular flake-like mesoporous $\mathrm{NiCo}_{2} \mathrm{O}_{4}$ as enzyme mimic for glucose biosensing and biofuel cell, Sci China Mater. 60 (2017) 766-776. doi:10.1007/s40843-017-9072-9.

[15] R. Chen, H.-Y. Wang, J. Miao, H. Yang, B. Liu, A flexible high-performance oxygen evolution electrode with three-dimensional $\mathrm{NiCO}_{2} \mathrm{O}_{4}$ core-shell nanowires, Nano Energy. 11 (2015) 333-340. doi:10.1016/j.nanoen.2014.11.021.

[16] B. Cai, W. Mao, Z. Ye, J. Huang, Facile fabrication of all-solid-state $\mathrm{SnO}_{2} / \mathrm{NiCo}_{2} \mathrm{O}_{4}$ biosensor for self-powered glucose detection, Appl Phys A. 122 (2016) 806. doi:10.1007/s00339-016-0263-9. 
[17] K.K. Naik, A. Gangan, B. Chakraborty, S.K. Nayak, C.S. Rout, Enhanced Nonenzymatic Glucose-Sensing Properties of Electrodeposited $\mathrm{NiCo}_{2} \mathrm{O}_{4}-\mathrm{Pd}$ Nanosheets: Experimental and DFT Investigations, ACS Appl Mater Interfaces. 9 (2017) 23894-23903. doi:10.1021/acsami.7b02217.

[18] S. Wang, S. Zhang, M. Liu, H. Song, J. Gao, Y. Qian, $\mathrm{MoS}_{2}$ as connector inspired high electrocatalytic performance of $\mathrm{NiCo}_{2} \mathrm{O}_{4}$ nanoplates towards glucose, Sens. Actuators $\mathrm{B}$ Chem. 254 (2018) 1101-1109. doi:10.1016/j.snb.2017.08.011.

[19] S. Chen, S.-Z. Qiao, Hierarchically Porous Nitrogen-Doped Graphene--NiCo $\mathrm{O}_{4}$ Hybrid Paper as an Advanced Electrocatalytic Water-Splitting Material, ACS Nano. 7 (2013) 10190-10196. doi:10.1021/nn404444r.

[20] L. Wang, X. Lu, Y. Ye, L. Sun, Y. Song, Nickel-cobalt nanostructures coated reduced graphene oxide nanocomposite electrode for nonenzymatic glucose biosensing, Electrochimica Acta. 114 (2013) 484-493. doi:10.1016/j.electacta.2013.10.125.

[21] G. George, S. Anandhan, Tuning characteristics of $\mathrm{Co}_{3} \mathrm{O}_{4}$ nanofiber mats developed for electrochemical sensing of glucose and $\mathrm{H}_{2} \mathrm{O}_{2}$, Thin Solid Films. 610 (2016) 48-57. doi:10.1016/j.tsf.2016.05.005.

[22] Y. Zhang, Y. Wang, J. Jia, J. Wang, Nonenzymatic glucose sensor based on graphene oxide and electrospun NiO nanofibers, Sens. Actuators B Chem. 171-172 (2012) 580587. doi:10.1016/j.snb.2012.05.037.

[23] G. George, L. Elias, A. Chitharanjan Hegde, S. Anandhan, Morphological and structural characterisation of sol-gel electrospun $\mathrm{Co}_{3} \mathrm{O}_{4}$ nanofibres and their electro-catalytic behaviour, RSC Adv. 5 (2015) 40940-40949. doi:10.1039/C5RA06368J.

[24] Y. Su, Q. Xu, Q. Zhong, S. Shi, C. Zhang, C. Xu, $\mathrm{NiCo}_{2} \mathrm{O}_{4} / \mathrm{C}$ prepared by one-step intermittent microwave heating method for oxygen evolution reaction in splitter, J. Alloys Compd. 617 (2014) 115-119. doi:10.1016/j.jallcom.2014.07.195.

[25] Y. Shao, J. Wang, H. Wu, J. Liu, I.A. Aksay, Y. Lin, Graphene Based Electrochemical Sensors and Biosensors: A Review, Electroanalysis. 22 (2010) 1027-1036. doi:10.1002/elan.200900571.

[26] T.-H. Ko, S. Radhakrishnan, M.-K. Seo, M.-S. Khil, H.-Y. Kim, B.-S. Kim, A green and scalable dry synthesis of $\mathrm{NiCO}_{2} \mathrm{O}_{4} /$ graphene nanohybrids for high-performance supercapacitor and enzymeless glucose biosensor applications, J. Alloys Compd. 696 (2017) 193-200. doi:10.1016/j.jallcom.2016.11.234.

[27] A. Mondal, S. Maiti, S. Mahanty, A. Baran Panda, Large-scale synthesis of porous $\mathrm{NiCo}_{2} \mathrm{O}_{4}$ and $\mathrm{rGO}-\mathrm{NiCo}_{2} \mathrm{O}_{4}$ hollow-spheres with superior electrochemical performance as faradaic electrode, J. Mater. Chem. A. 5 (2017) 16854-16864. doi:10.1039/C7TA03491A.

[28] W. Huang, T. Lin, Y. Cao, X. Lai, J. Peng, J. Tu, Hierarchical $\mathrm{NiCo}_{2} \mathrm{O}_{4}$ Hollow Sphere as a Peroxidase Mimetic for Colorimetric Detection of $\mathrm{H}_{2} \mathrm{O}_{2}$ and Glucose, Sensors. 17 (2017) 217. doi:10.3390/s17010217.

[29] K.K. Naik, S. Kumar, C.S. Rout, Electrodeposited spinel $\mathrm{NiCo}_{2} \mathrm{O}_{4}$ nanosheet arrays for glucose sensing application, RSC Adv. 5 (2015) 74585-74591. doi:10.1039/C5RA13833G.

[30] H. Yin, T. Zhan, D. Qin, X. He, Q. Nie, J. Gong, Self-assembly of dandelion-like $\mathrm{NiCo}_{2} \mathrm{O}_{4}$ hierarchical microspheres for non-enzymatic glucose sensor, Inorg. Nano-Met. Chem. 47 (2017) 1560-1567. doi:10.1080/24701556.2017.1357610.

[31] Z. Qin, Q. Cheng, Y. Lu, J. Li, Facile synthesis of hierarchically mesoporous $\mathrm{NiCo}_{2} \mathrm{O}_{4}$ nanowires for sensitive nonenzymatic glucose detection, Appl Phys A. 123 (2017) 492. doi:10.1007/s00339-017-1108-x.

[32] H. Rao, Z. Zhang, H. Ge, X. Liu, P. Zou, X. Wang, Y. Wang, Enhanced amperometric sensing using a $\mathrm{NiCo}_{2} \mathrm{O}_{4} /$ nitrogen-doped reduced graphene oxide/ionic liquid ternary 
composite for enzyme-free detection of glucose, New J. Chem. 41 (2017) 3667-3676. doi:10.1039/C7NJ00077D.

[33] M. Saraf, K. Natarajan, S. M. Mobin, Multifunctional porous $\mathrm{NiCo}_{2} \mathrm{O}_{4}$ nanorods: sensitive enzymeless glucose detection and supercapacitor properties with impedance spectroscopic investigations, New J. Chem. 41 (2017) 9299-9313. doi:10.1039/C7NJ01519D.

[34] B.S. Kumar, V.C. Gudla, R. Ambat, S.K. Kalpathy, S. Anandhan, A Mechanistic Study on the Structure Formation of $\mathrm{NiCo}_{2} \mathrm{O}_{4}$ Nanofibers Decorated with In Situ Formed Graphene-Like Structures, J Inorg Organomet Polym. (2018) 1-16. doi:10.1007/s10904018-0842-7.

[35] K.R. Murali, P. Muthusamy, A. Panneerselvam, Characteristics of brush plated copper indium telluride films, J. Mater. Sci. Mater. Electron. 24 (2013) 3412-3417. doi:10.1007/s10854-013-1263-6.

[36] S. Sen, S.K. Halder, S.P.S. Gupta, An X-ray line profile analysis in vacuum-evaporated silver films, J. Phys. Appl. Phys. 8 (1975) 1709-1721. doi:10.1088/0022-3727/8/15/005.

[37] Y.P.V. Subbaiah, P. Prathap, K.T.R. Reddy, Structural, electrical and optical properties of ZnS films deposited by close-spaced evaporation, Appl. Surf. Sci. 253 (2006) 24092415. doi:10.1016/j.apsusc.2006.04.063.

[38] E. Rafiee, M. Farzam, M.A. Golozar, A. Ashrafi, An Investigation on Dislocation Density in Cold-Rolled Copper Using Electrochemical Impedance Spectroscopy, ISRN Corros. 2013 (2013) 6. doi:https://doi.org/10.1155/2013/921825.

[39] C.W. Lee, S.-D. Seo, D.W. Kim, S. Park, K. Jin, D.-W. Kim, K.S. Hong, Heteroepitaxial growth of $\mathrm{ZnO}$ nanosheet bands on $\mathrm{ZnCo}_{2} \mathrm{O}_{4}$ submicron rods toward high-performance Li ion battery electrodes, Nano Res. 6 (2013) 348-355. doi:10.1007/s12274-013-0311-0.

[40] F.A. Permatasari, A.H. Aimon, F. Iskandar, T. Ogi, K. Okuyama, Role of C-N Configurations in the Photoluminescence of Graphene Quantum Dots Synthesized by a Hydrothermal Route, Sci. Rep. 6 (2016) srep21042. doi:10.1038/srep21042.

[41] K. Yan, L.-B. Kong, Y.-H. Dai, M. Shi, K.-W. Shen, B. Hu, Y.-C. Luo, L. Kang, Design and preparation of highly structure-controllable mesoporous carbons at the molecular level and their application as electrode materials for supercapacitors, J. Mater. Chem. A. 3 (2015) 22781-22793. doi:10.1039/C5TA05947J.

[42] G. Singh, A. Choudhary, D. Haranath, A.G. Joshi, N. Singh, S. Singh, R. Pasricha, ZnO decorated luminescent graphene as a potential gas sensor at room temperature, Carbon. 50 (2012) 385-394. doi:10.1016/j.carbon.2011.08.050.

[43] C.P. Sajan, A. Naik, H.N. Girish, H.R. Ravi, R. Singh, Template-Free Processing of AgAnchored $\mathrm{ZnO}$ Polyscale Sheets and Their Application in the Photocatalytic Degradation of Organics Present in Pharmaceutical Waste, Water Conserv Sci Eng. 2 (2017) 31-41. doi:10.1007/s41101-017-0022-6.

[44] M. Schulze, M. v Bradke, R. Reissner, M. Lorenz, E. Gülzow, Characterization of polymers in PEFC-electrodes with EDX and XPS, Fresenius J Anal Chem. 365 (1999) 123-132. doi:10.1007/s002160051457.

[45] B.S. Kumar, C. Dhanasekhar, A. Venimadhav, S.K. Kalpathy, S. Anandhan, Pyrolysiscontrolled synthesis, and magnetic properties of sol-gel electrospun nickel cobaltite nanostructures, J Sol-Gel Sci Technol. $86 \quad$ (2018) 664-674. doi:https://doi.org/10.1007/s10971-018-4672-4.

[46] R. Ding, L. Qi, M. Jia, H. Wang, Simple hydrothermal synthesis of mesoporous spinel $\mathrm{NiCO}_{2} \mathrm{O}_{4}$ nanoparticles and their catalytic behavior in $\mathrm{CH}_{3} \mathrm{OH}$ electro-oxidation and $\mathrm{H}_{2} \mathrm{O}_{2}$ electro-reduction, Catal Sci Technol. 3 (2013) 3207-3215. doi:10.1039/C3CY00590A. 
[47] Y. Wang, K. Cheng, D. Cao, F. Yang, P. Yan, W. Zhang, G. Wang, Preparation of $\mathrm{NiCo}_{2} \mathrm{O}_{4}$ Nanosheet Arrays and its High Catalytic Performance for $\mathrm{H}_{2} \mathrm{O}_{2}$ Electroreduction, Fuel Cells. 15 (2015) 298-305. doi:10.1002/fuce.201300299.

[48] E. Umeshbabu, G. Rajeshkhanna, P. Justin, G.R. Rao, $\mathrm{NiCo}_{2} \mathrm{O}_{4} / \mathrm{rGO}$ hybrid nanostructures for efficient electrocatalytic oxygen evolution, J Solid State Electrochem. 20 (2016) 2725-2736. doi:10.1007/s10008-016-3278-4.

[49] H. Huang, C. Liu, L. Ni, C. Zhou, Evaluation of microstructural evolution of thermal barrier coatings exposed to $\mathrm{Na}_{2} \mathrm{SO}_{4}$ using impedance spectroscopy, Corros. Sci. 53 (2011) 1369-1374. doi:10.1016/j.corsci.2010.12.023.

[50] K.S. Bhat, H.C. Barshilia, H.S. Nagaraja, Porous nickel telluride nanostructures as bifunctional electrocatalyst towards hydrogen and oxygen evolution reaction, Int. J. Hydrog. Energy. 42 (2017) 24645-24655. doi:10.1016/j.ijhydene.2017.08.098.

[51] D. Un Lee, B. Jung Kim, Z. Chen, One-pot synthesis of a mesoporous $\mathrm{NiCo}_{2} \mathrm{O}_{4}$ nanoplatelet and graphene hybrid and its oxygen reduction and evolution activities as an efficient bi-functional electrocatalyst, J. Mater. Chem. A. 1 (2013) 4754-4762. doi:10.1039/C3TA01402A.

[52] J. Yang, M. Cho, Y. Lee, Synthesis of hierarchical $\mathrm{NiCo}_{2} \mathrm{O}_{4}$ hollow nanorods via sacrificial-template accelerate hydrolysis for electrochemical glucose oxidation, Biosens. Bioelectron. 75 (2016) 15-22. doi:10.1016/j.bios.2015.08.008.

[53] M. Wu, S. Meng, Q. Wang, W. Si, W. Huang, X. Dong, Nickel-Cobalt Oxide Decorated Three-Dimensional Graphene as an Enzyme Mimic for Glucose and Calcium Detection, ACS Appl Mater Interfaces. 7 (2015) 21089-21094. doi:10.1021/acsami.5b06299.

[54] X. Tang, B. Zhang, C. Xiao, H. Zhou, X. Wang, D. He, Carbon nanotube template synthesis of hierarchical $\mathrm{NiCoO}_{2}$ composite for non-enzyme glucose detection, Sens. Actuators B Chem. 222 (2016) 232-239. doi:10.1016/j.snb.2015.08.077.

[55] G. Ma, M. Yang, C. Li, H. Tan, L. Deng, S. Xie, F. Xu, L. Wang, Y. Song, Preparation of spinel nickel-cobalt oxide nanowrinkles/reduced graphene oxide hybrid for nonenzymatic glucose detection at physiological level, Electrochimica Acta. 220 (2016) 545-553. doi:10.1016/j.electacta.2016.10.163.

[56] M. Hussain, Z.H. Ibupoto, M.A. Abbasi, X. Liu, O. Nur, M. Willander, Synthesis of Three Dimensional Nickel Cobalt Oxide Nanoneedles on Nickel Foam, Their Characterization and Glucose Sensing Application, Sensors. 14 (2014) 5415-5425. doi:10.3390/s140305415.

[57] Z. Yu, H. Li, X. Zhang, N. Liu, W. Tan, X. Zhang, L. Zhang, Facile synthesis of $\mathrm{NiCo}_{2} \mathrm{O}_{4} @$ Polyaniline core-shell nanocomposite for sensitive determination of glucose, Biosens. Bioelectron. 75 (2016) 161-165. doi:10.1016/j.bios.2015.08.024.

[58] H. Liang, F. Meng, M. Cabán-Acevedo, L. Li, A. Forticaux, L. Xiu, Z. Wang, S. Jin, Hydrothermal Continuous Flow Synthesis and Exfoliation of NiCo Layered Double Hydroxide Nanosheets for Enhanced Oxygen Evolution Catalysis, Nano Lett. 15 (2015) 1421-1427. doi:10.1021/n1504872s.

[59] H. Shi, G. Zhao, Water Oxidation on Spinel $\mathrm{NiCo}_{2} \mathrm{O}_{4}$ Nanoneedles Anode: Microstructures, Specific Surface Character, and the Enhanced Electrocatalytic Performance, J Phys Chem C. 118 (2014) 25939-25946. doi:10.1021/jp508977j.

[60] W.-Y. Xia, N. Li, Q.-Y. Li, K.-H. Ye, C.-W. Xu, Au-NiCo $\mathrm{O}_{4}$ supported on threedimensional hierarchical porous graphene-like material for highly effective oxygen evolution reaction, Sci. Rep. 6 (2016) 23398. doi:10.1038/srep23398.

[61] C. Xiao, Y. Li, X. Lu, C. Zhao, Bifunctional Porous NiFe/ $/ \mathrm{NiCo}_{2} \mathrm{O}_{4} / \mathrm{Ni}$ Foam Electrodes with Triple Hierarchy and Double Synergies for Efficient Whole Cell Water Splitting, Adv Funct Mater. 26 (2016) 3515-3523. doi:10.1002/adfm.201505302. 
[62] L. An, L. Huang, P. Zhou, J. Yin, H. Liu, P. Xi, A Self-Standing High-Performance Hydrogen Evolution Electrode with Nanostructured $\mathrm{NiCo}_{2} \mathrm{O}_{4} / \mathrm{CuS}$ Heterostructures, Adv Funct Mater. 25 (2015) 6814-6822. doi:10.1002/adfm.201503784.

[63] J. Yin, P. Zhou, L. An, L. Huang, C. Shao, J. Wang, H. Liu, P. Xi, Self-supported nanoporous $\mathrm{NiCo}_{2} \mathrm{O}_{4}$ nanowires with cobalt-nickel layered oxide nanosheets for overall water splitting, Nanoscale. 8 (2016) 1390-1400. doi:10.1039/C5NR06197K.

[64] X. Yu, Z. Sun, Z. Yan, B. Xiang, X. Liu, P. Du, Direct growth of porous crystalline $\mathrm{NiCo}_{2} \mathrm{O}_{4}$ nanowire arrays on a conductive electrode for high-performance electrocatalytic water oxidation, J. Mater. Chem. A. 2 (2014) 20823-20831. doi:10.1039/C4TA05315J.

[65] X. Liu, J. Liu, Y. Li, Y. Li, X. Sun, $\mathrm{Au} / \mathrm{NiCo}_{2} \mathrm{O}_{4}$ Arrays with High Activity for Water Oxidation, ChemCatChem. 6 (2014) 2501-2506. doi:10.1002/cctc.201402217.

[66] Y.-Z. Su, Q.-Z. Xu, G.-F. Chen, H. Cheng, N. Li, Z.-Q. Liu, One dimensionally spinel $\mathrm{NiCo}_{2} \mathrm{O}_{4}$ nanowire arrays: facile synthesis, water oxidation, and magnetic properties, Electrochimica Acta. 174 (2015) 1216-1224. doi:10.1016/j.electacta.2015.06.092. 


\section{Caption to figures}

Figure 1: Schematic showing test set-up for electrocatalytic studies.

Figure 2: (a-c) HRTEM and (d-f) lattice fringe images, (g-h) SAED patterns and (inset $\mathrm{g}-\mathrm{h}$ ) XRD patterns of GNC/NCO-NF obtained at different calcination soaking times. Arrows in HRTEM images indicate GNC.

Figure 3: High-resolution XPS depth profiling of NCO-4 nanofibers for Ni $2 p$ (a-c), Co $2 p$ (d-f), O $1 s$ (g-i), and C $1 s(\mathrm{j}-1)$.

Figure 4: (a) CV curves of bare GE and GE loaded with GNC/NCO-NF obtained at different calcination soaking times for a glucose concentration of $1 \mathrm{mM}$. CV curves of bare GE and GE loaded with NCO-4 nanofibers in presence of (b) $1 \mathrm{mM}$ glucose and (c) $100 \mu \mathrm{M} \mathrm{H} \mathrm{H}_{2} \mathrm{O}_{2}$.

Figure 5: (a) Cyclic voltammograms at various scan rates for GE loaded with NCO-4 nanofibers, in presence of $1 \mathrm{mM}$ glucose. (b) Linear fits of anodic current vs scan rates for both the cations.

Figure 6: (a) Amperometric response of NCO-4 nanofibers loaded GE for successive addition of glucose to electrolyte, (b) Response time observed for single addition of glucose, and (c) calibration curve for glucose detection using NCO-4/GE.

Figure 7: (a) Amperometric response of NCO-4 nanofibers loaded GE for successive addition of $\mathrm{H}_{2} \mathrm{O}_{2}$ to electrolyte, (b) Response time observed for single addition of $\mathrm{H}_{2} \mathrm{O}_{2}$, and (c) calibration curve for $\mathrm{H}_{2} \mathrm{O}_{2}$ sensing using $\mathrm{NCO}-4 / \mathrm{GE}$.

Figure 8: Nyquist plots for NCO-4/GE in absence and presence of analytes, (a) $1 \mathrm{mM}$ glucose and (b) $100 \mu \mathrm{M} \mathrm{H}_{2} \mathrm{O}_{2}$. (c) Randles equivalent circuit fitted for EIS spectra.

Figure 9: CV curves (inset CP plots) of NCO-4/GE obtained for (a) HER and (b) OER. (c) Tafel polarisation plot at a slow scan rate of $5 \mathrm{mV} \cdot \mathrm{s}^{-1}$. 
Table 1: Circuit parameters obtained for Randles equivalent fitting.

\begin{tabular}{|c|r|r|r|r|}
\hline Parameter & \multicolumn{1}{|c|}{ Bare GE } & \multicolumn{1}{|c|}{$\begin{array}{c}\text { NCO-4/GE in } \\
\text { absence of } \\
\text { analytes }\end{array}$} & $\begin{array}{r}\text { NCO-4/GE in } \\
\text { presence of 1 } \\
\text { mM glucose }\end{array}$ & $\begin{array}{r}\text { NCO-4/GE in } \\
\text { presence of 100 } \\
\boldsymbol{\mu M} \boldsymbol{H}_{2} \boldsymbol{O}_{2}\end{array}$ \\
\hline$R_{\text {elect }}(\Omega)$ & 23.17 & 28.24 & 28.77 & 31.52 \\
\hline$R_{c t}(\Omega)$ & 497300 & 261450 & 26440 & 277.4 \\
\hline$Q_{C P E}\left(\mathrm{~F} \cdot \mathrm{s}^{\mathrm{n}-1}\right)$ & $0.1367 \times 10^{-3}$ & $1.88 \times 10^{-3}$ & $1.709 \times 10^{-3}$ & $1.904 \times 10^{-3}$ \\
\hline$a$ & 0.9 & 0.9425 & 0.9239 & 0.8779 \\
\hline$C_{d l}(\mu \mathrm{F})$ & 218.46 & 2743.87 & 2339.17 & 1742.25 \\
\hline
\end{tabular}


Table 2: Performance comparison of NCO based glucose and $\mathrm{H}_{2} \mathrm{O}_{2}$ biosensors.

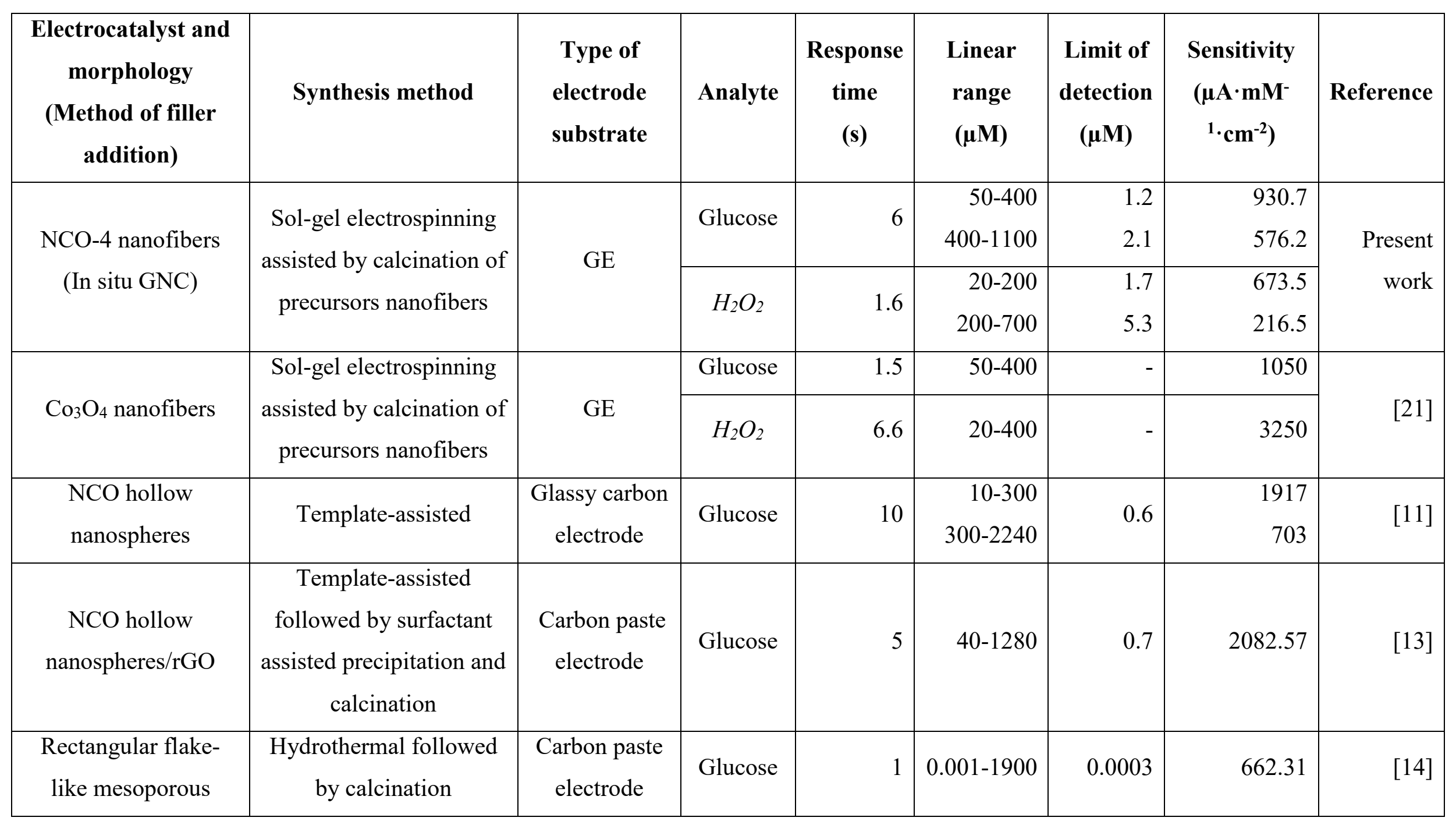




\begin{tabular}{|c|c|c|c|c|c|c|c|c|}
\hline $\mathrm{NCO}$ & & & & & & & & \\
\hline NCO nanosheets & \multirow[b]{2}{*}{ Electrodeposition } & \multirow[b]{2}{*}{$\mathrm{Ni}$ foam } & \multirow[b]{2}{*}{ Glucose } & \multirow[b]{2}{*}{ - } & \multirow[b]{2}{*}{$5-90$} & 2.46 & 27500 & \multirow[b]{2}{*}[17]{} \\
\hline $\begin{array}{c}\text { NCO-Pd nanosheets } \\
\text { (Solution) }\end{array}$ & & & & & & 0.28 & 40030 & \\
\hline $\begin{array}{c}\mathrm{MoS}_{2}-\mathrm{NCO} \\
\text { nanoplates } \\
\text { (Dispersion) }\end{array}$ & $\begin{array}{c}\text { Hydrothermal followed } \\
\text { by calcination }\end{array}$ & $\begin{array}{c}\text { Glassy carbon } \\
\text { electrode }\end{array}$ & Glucose & 5 & $1-1600$ & 0.152 & 1748.58 & [18] \\
\hline $\begin{array}{c}\mathrm{NCO} / \mathrm{rGO} \\
(\pi-\pi \text { interaction and } \\
\text { dynamic potential } \\
\text { scan })\end{array}$ & Electrodeposition & $\begin{array}{c}\text { Glassy carbon } \\
\text { electrode }\end{array}$ & Glucose & 2 & $10-2650$ & 3.79 & 1773.61 & [20] \\
\hline Urchin-like NCO & $\begin{array}{c}\text { Hydrothermal followed } \\
\text { by calcination }\end{array}$ & $\begin{array}{c}\text { Glassy carbon } \\
\text { electrode }\end{array}$ & Glucose & 1 & $0.37-2000$ & 0.37 & 72.4 & [31] \\
\hline $\begin{array}{c}\text { NCO/N-rGO/IL } \\
\text { (Dispersion) }\end{array}$ & $\begin{array}{l}\text { Hydrothermal followed } \\
\text { by calcination }\end{array}$ & $\begin{array}{c}\text { Glassy carbon } \\
\text { electrode }\end{array}$ & Glucose & 2 & $1-4555$ & 0.18 & 3760 & [32] \\
\hline NCO nanorods & $\begin{array}{c}\text { Hydrothermal followed } \\
\text { by calcination }\end{array}$ & $\begin{array}{c}\text { Glassy carbon } \\
\text { electrode }\end{array}$ & Glucose & 3 & $1-880$ & 0.063 & 4710 & [33] \\
\hline NCO hierarchical & Sacrificial template & Stainless steel & Glucose & 2 & $0.3-1000$ & 0.16 & 1685.1 & [52] \\
\hline
\end{tabular}




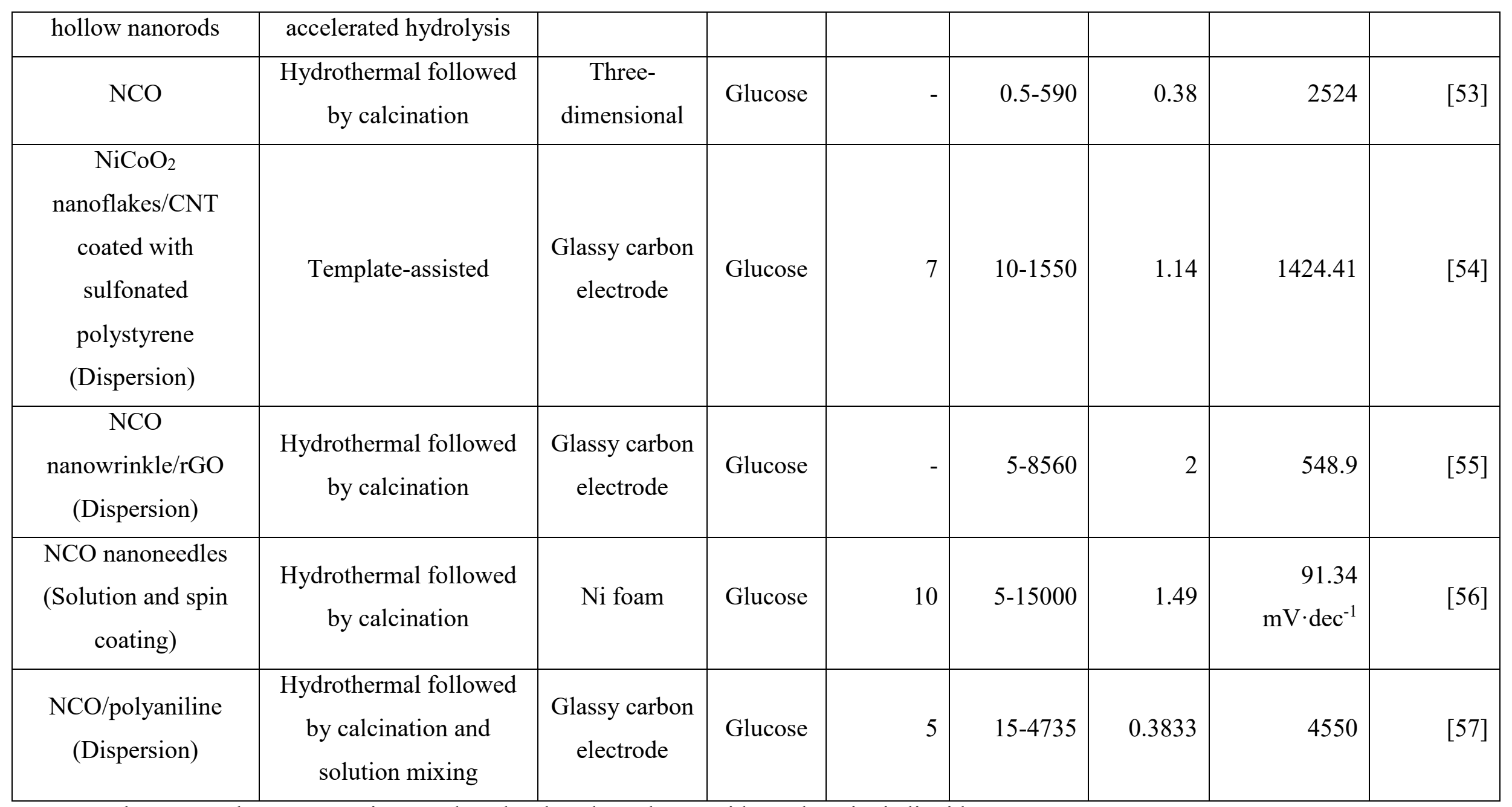

CNT: Carbon nanotube, N-rGO: nitrogen doped-reduced graphene oxide, and IL: ionic liquid. 
Table 3: Collation of electrocatalytic HER and OER characteristics for NCO based material.

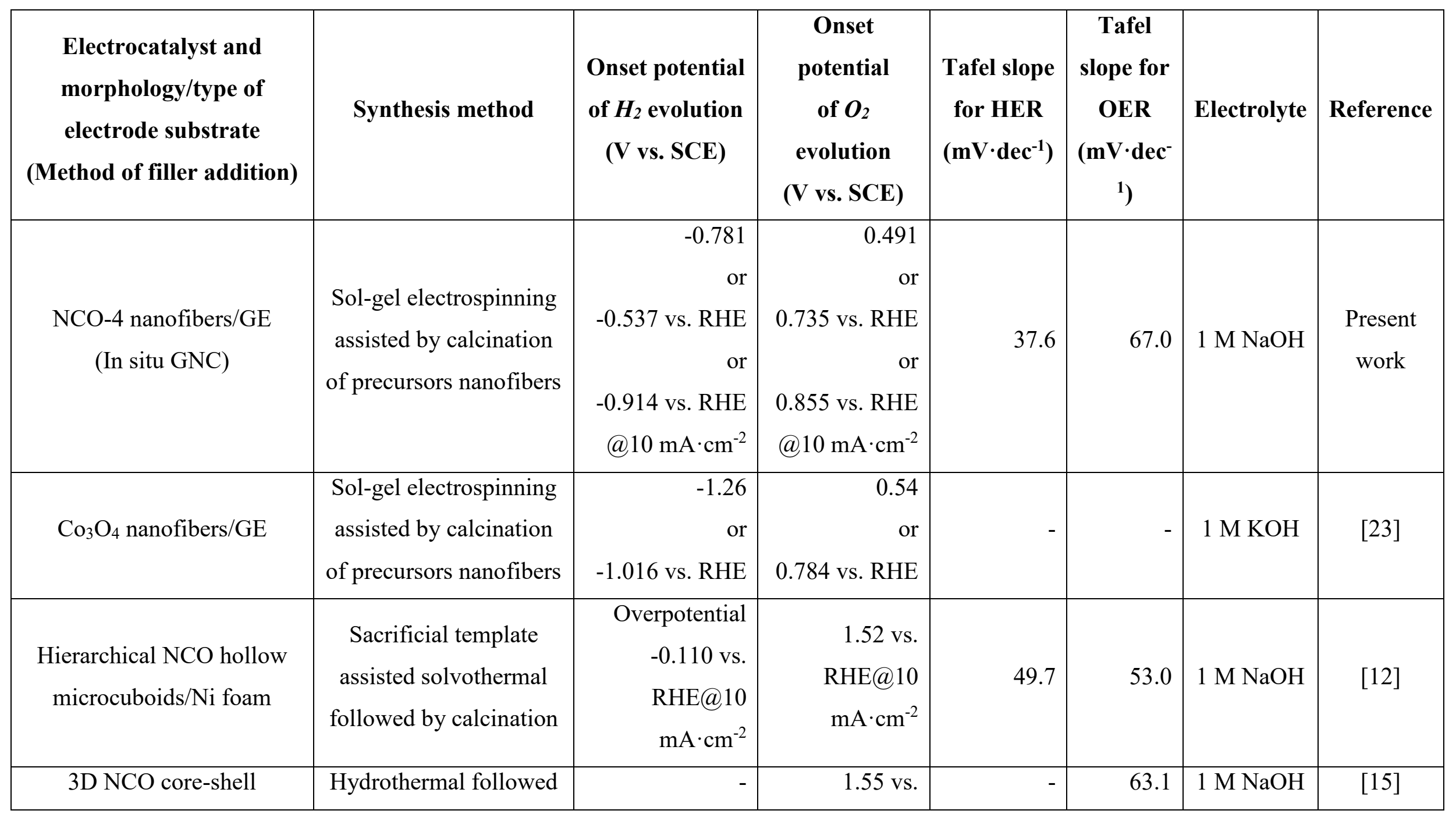




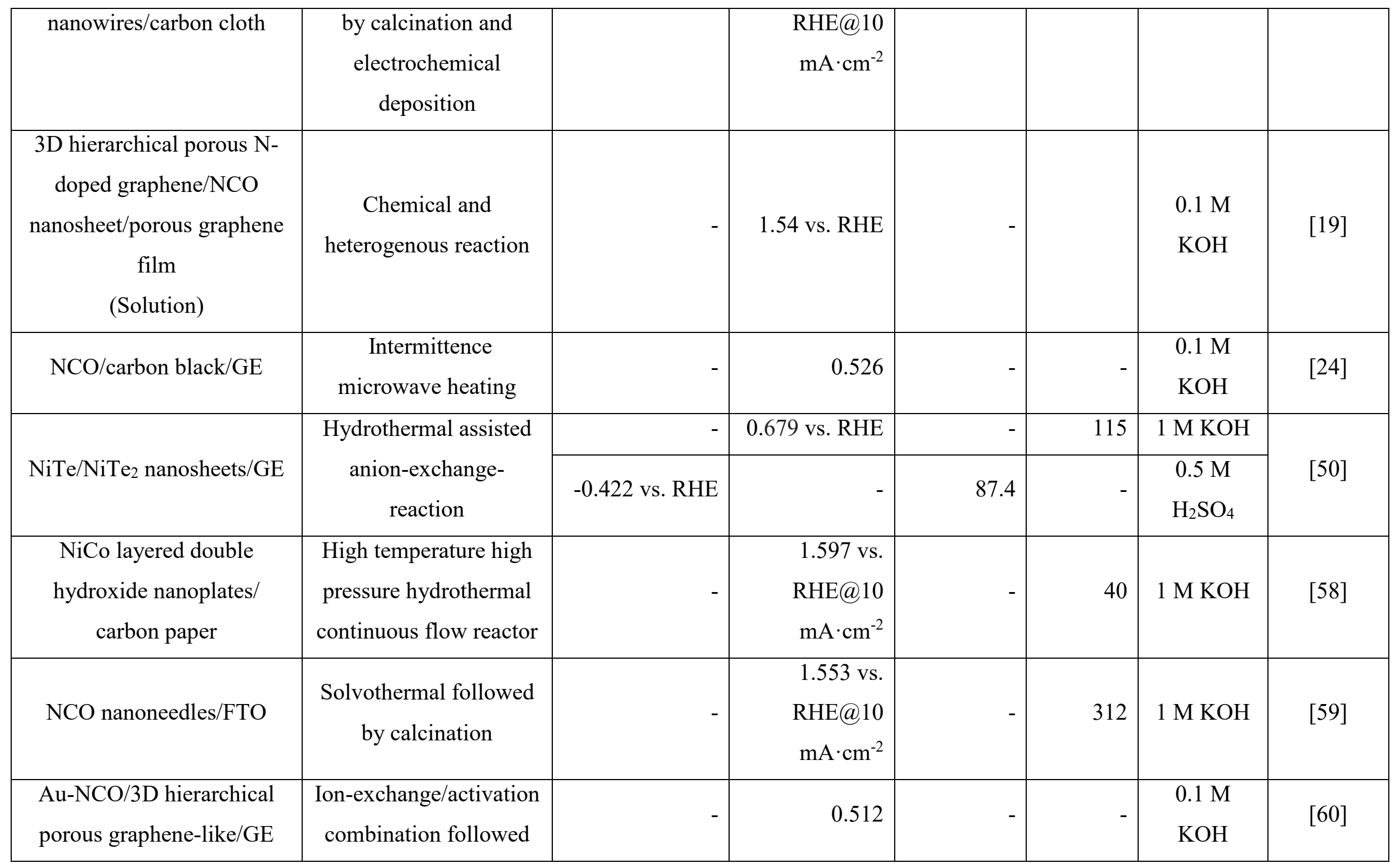




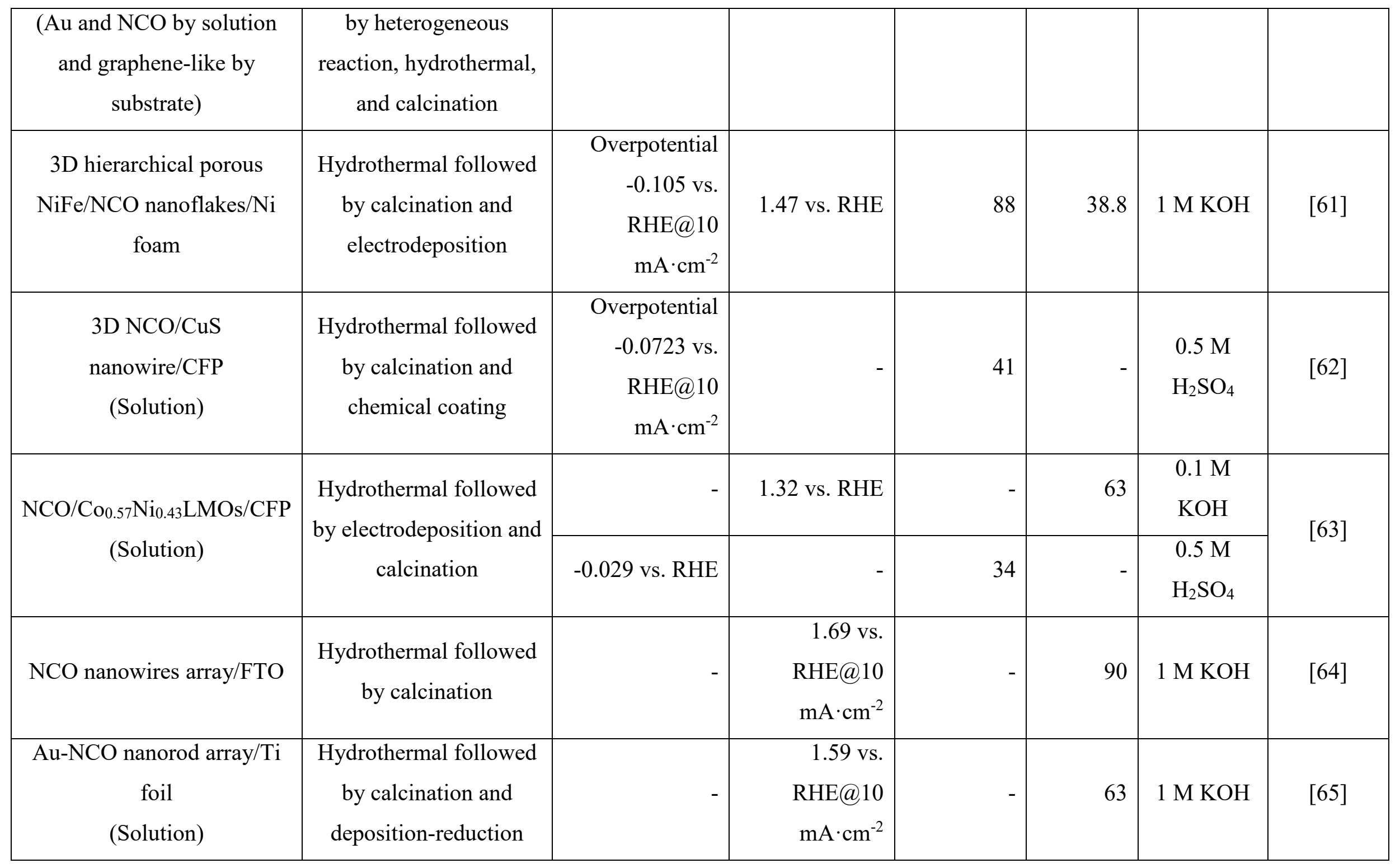




\begin{tabular}{|c|c|c|r|r|r|r|}
\hline $\begin{array}{c}\text { 1D NCO nanowire } \\
\text { array/Carbon rod }\end{array}$ & $\begin{array}{c}\text { Hydrothermal followed } \\
\text { by calcination }\end{array}$ & - & 0.5 & - & 62 & $1 \mathrm{M} \mathrm{KOH}$ \\
\hline
\end{tabular}

$\mathrm{E}_{\mathrm{RHE}}=\mathrm{E}_{\mathrm{SCE}}+0.244 \mathrm{~V}$, Onset potential of OER = overpotential + 1.23 V, D: dimensional, GE: graphite electrode, FTO: fluorine-doped tin oxide, CFP: carbon fiber paper, and LMO: layered mixed oxide nanosheets. 


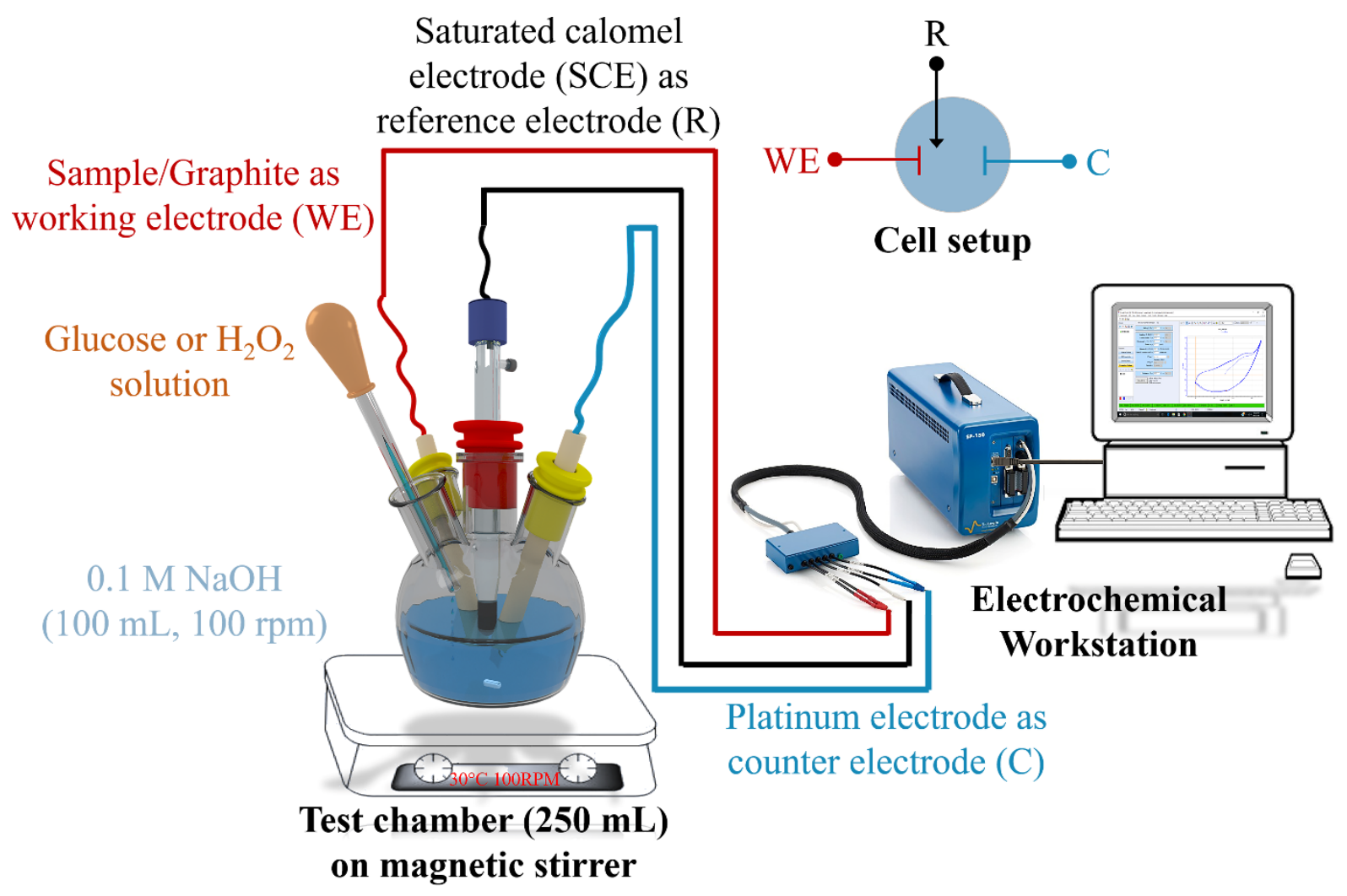

Figure 1 


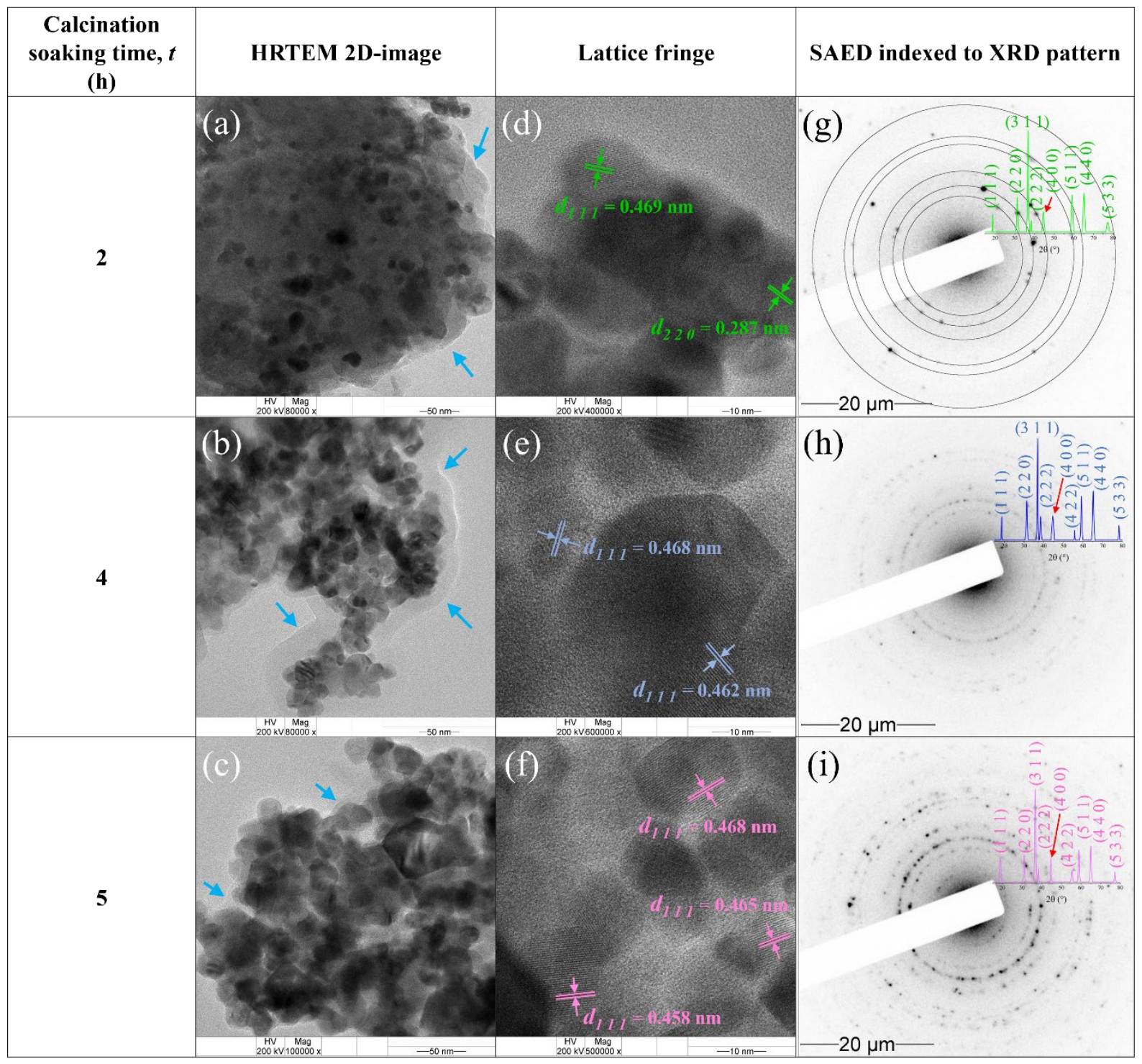

Figure 2 


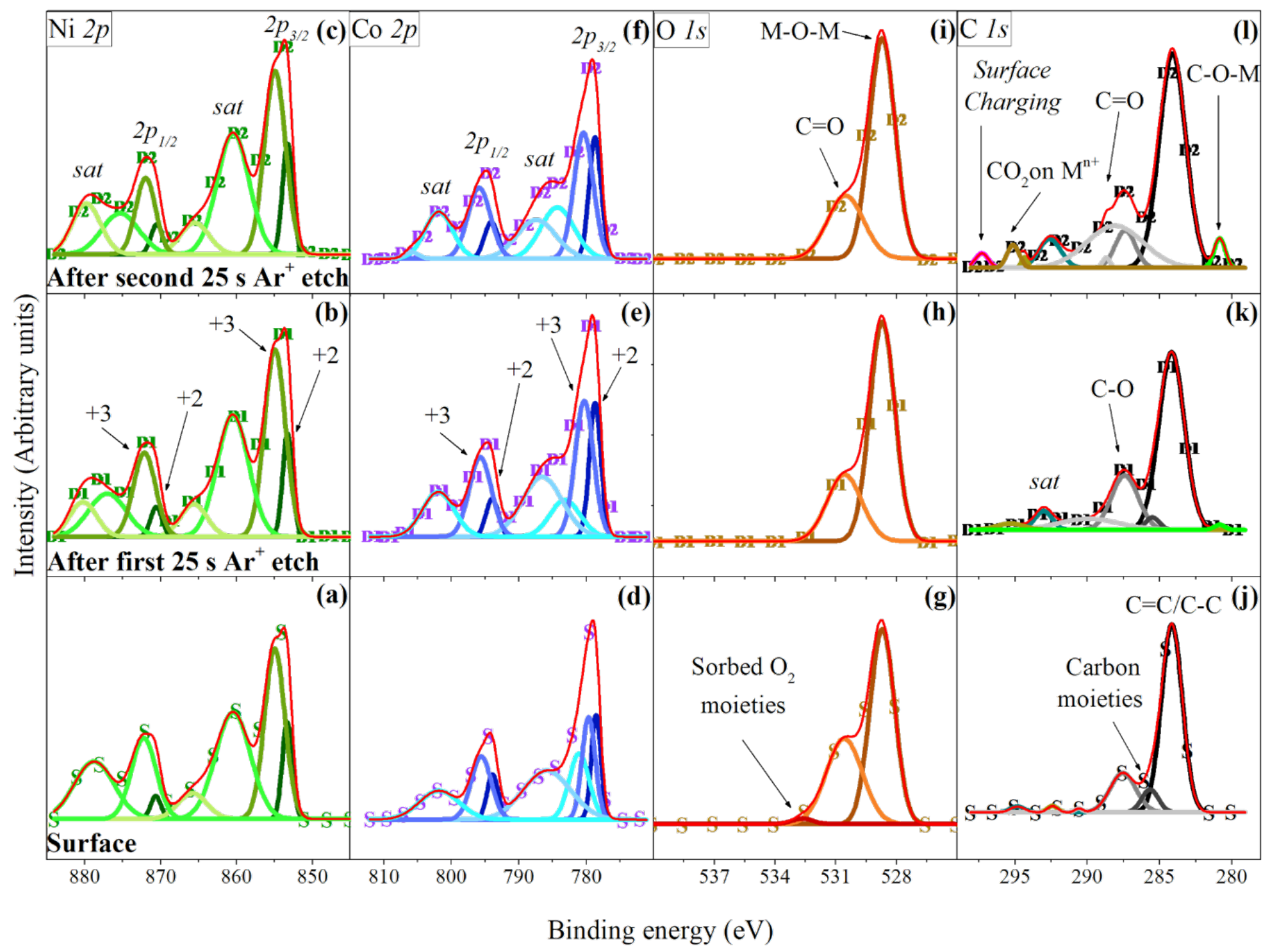

Figure 3 
(a)

(b)

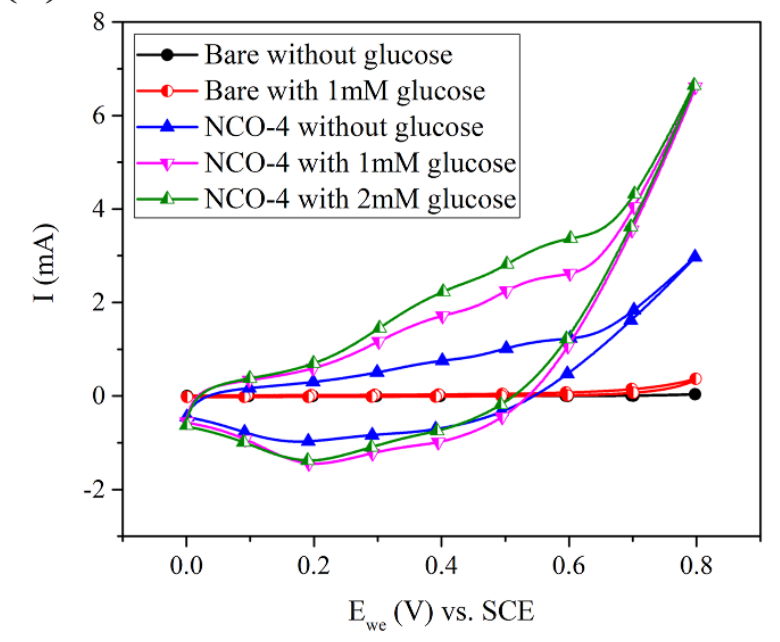

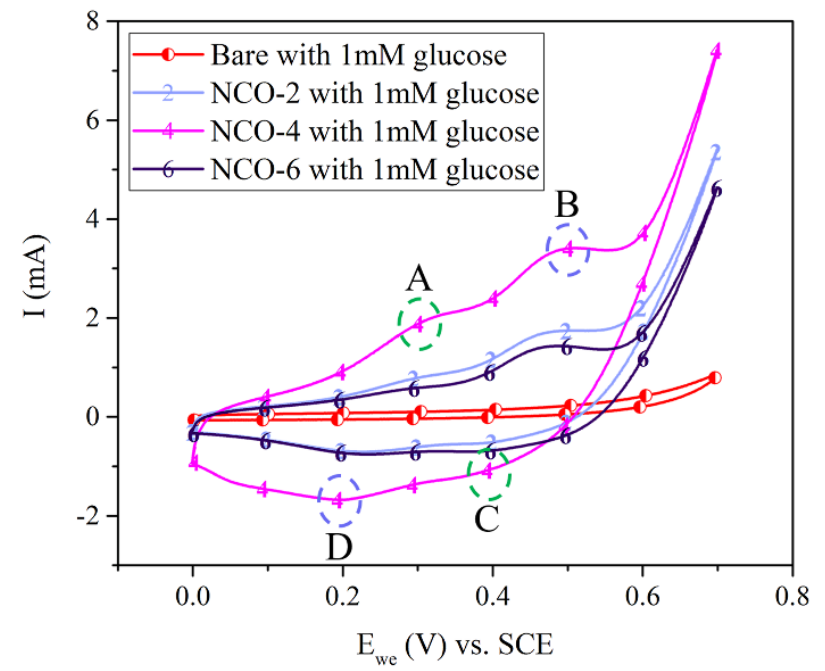

(c)

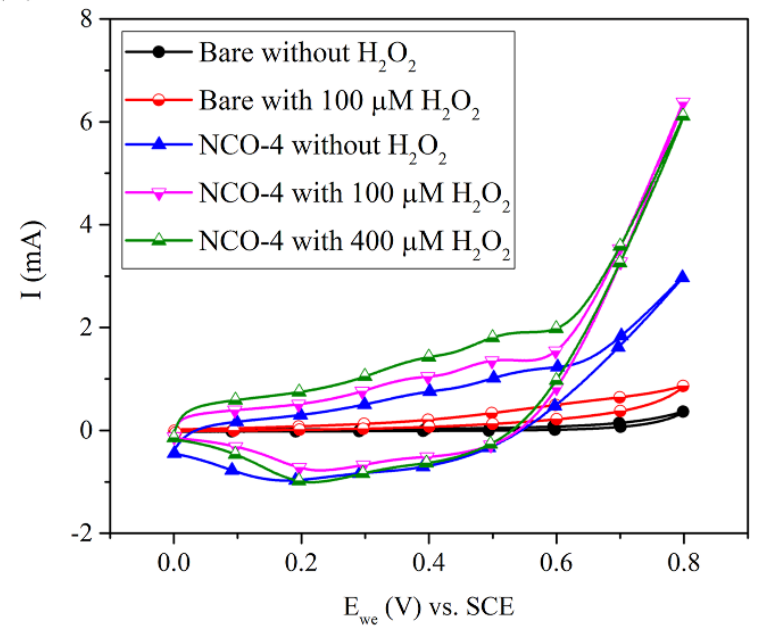

Figure 4 
(a)

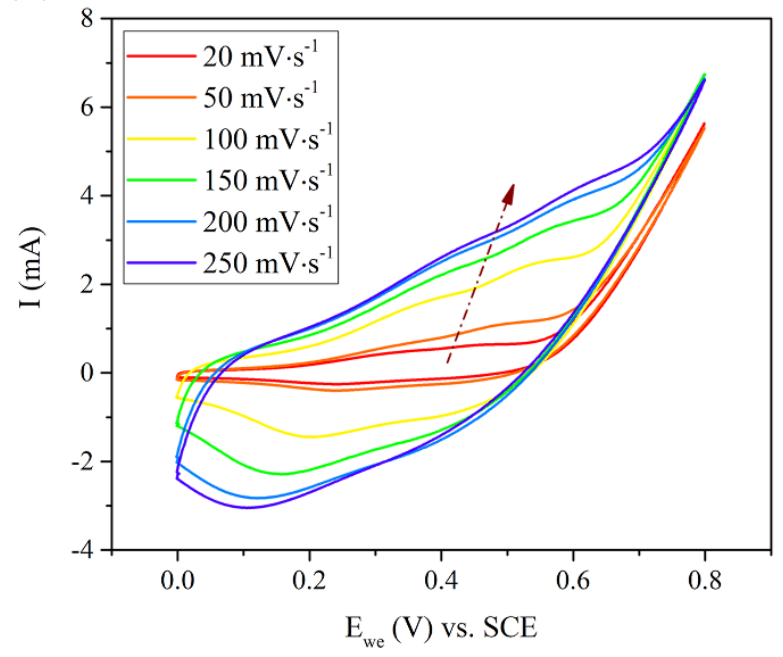

(b)

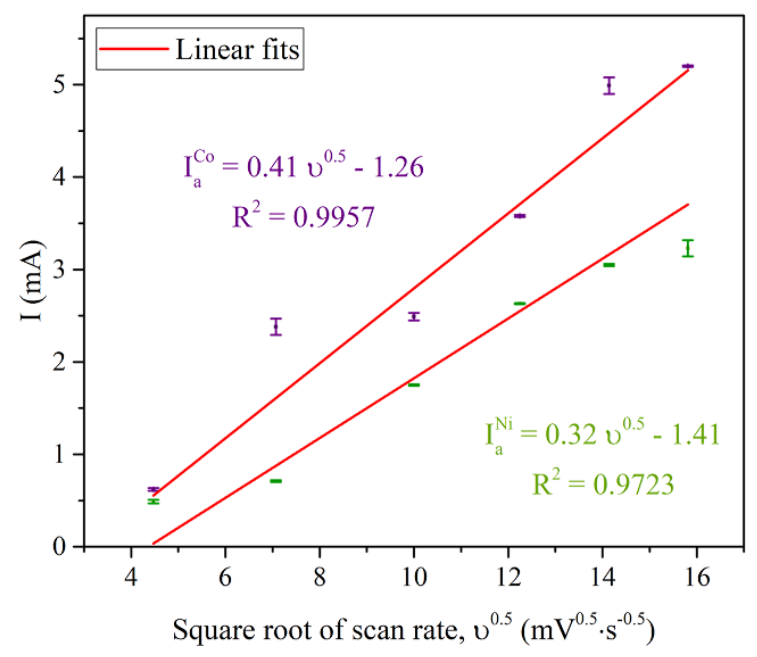

Figure 5 
(a)

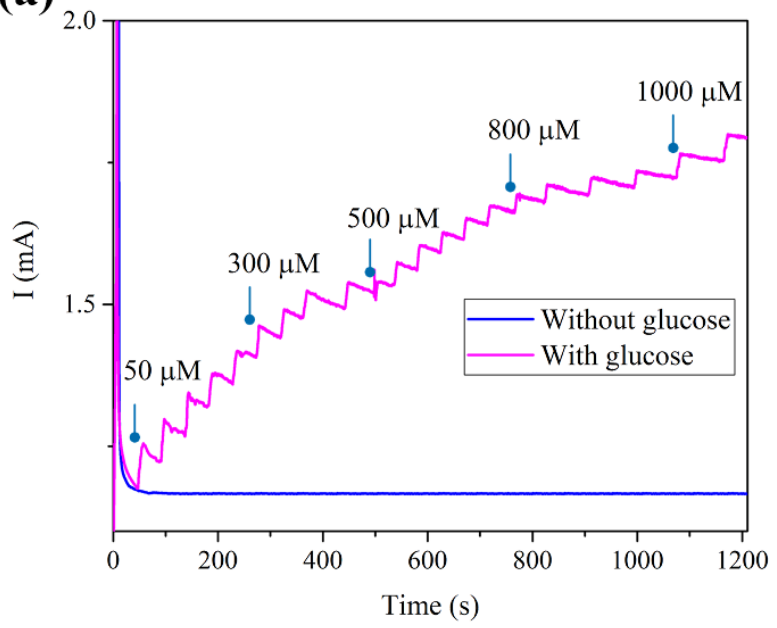

(b)

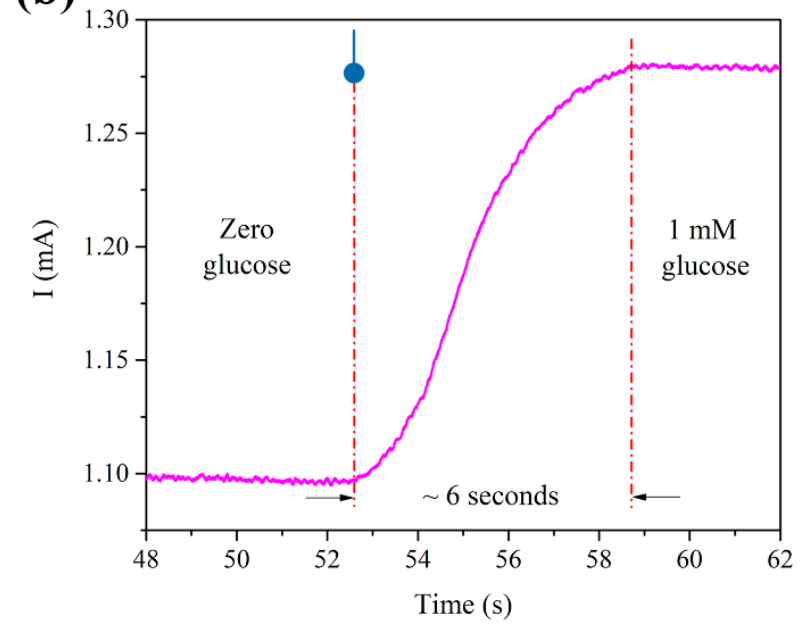

(c)

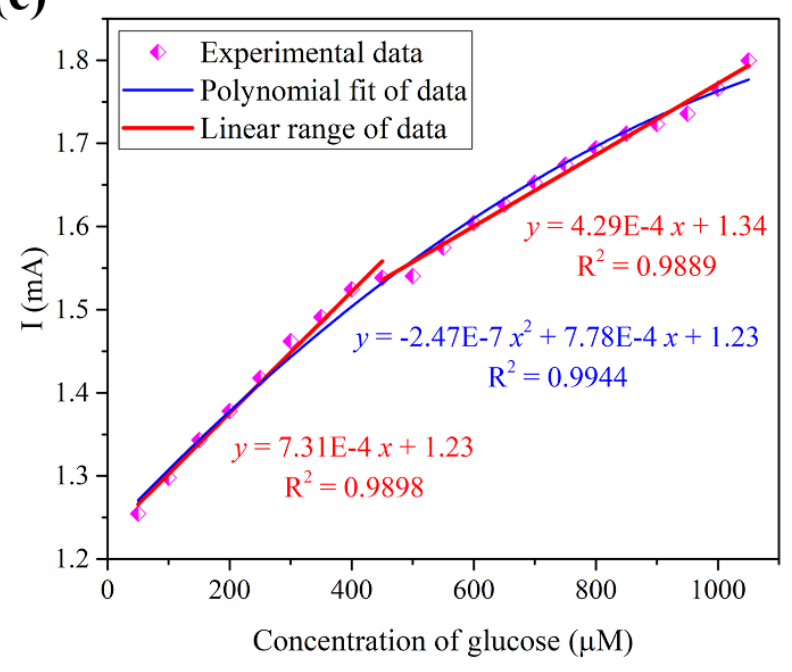

Figure 6 
(a)

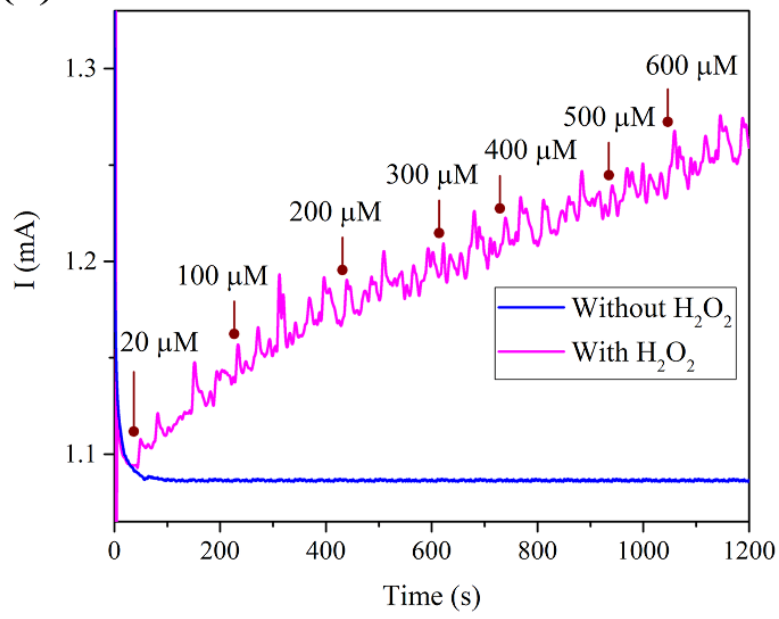

(b)

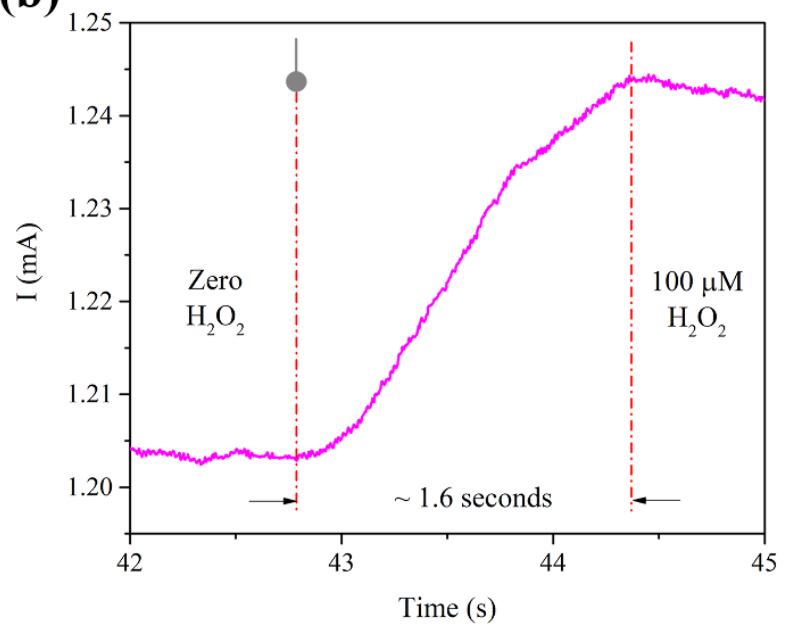

(c)

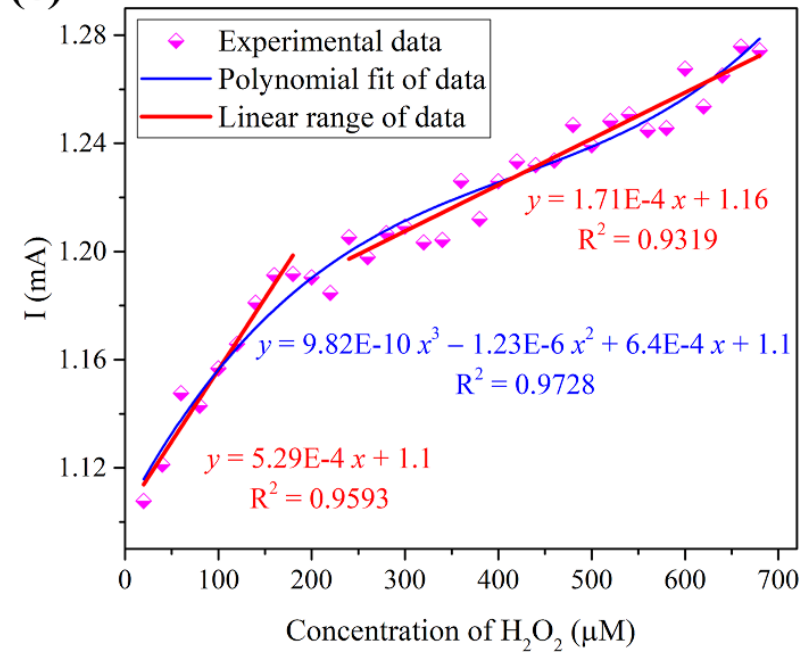

Figure 7 
(a)

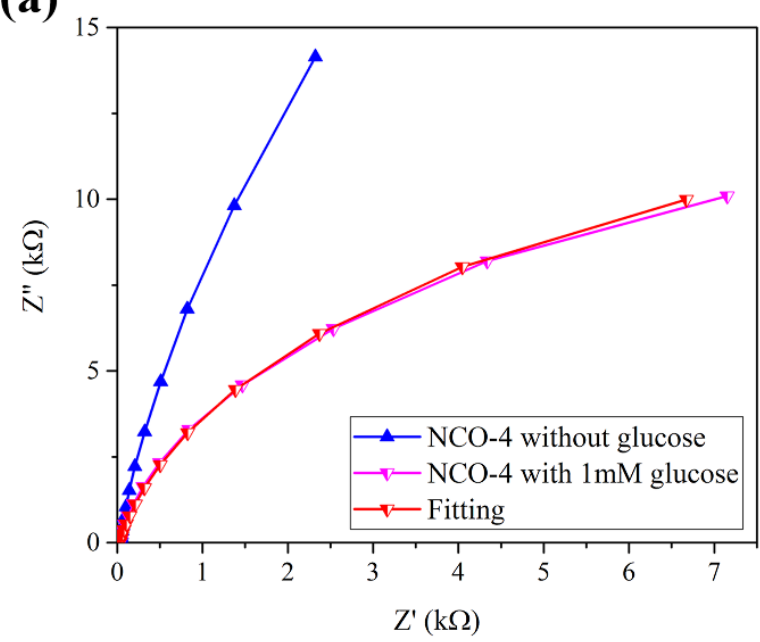

(b)

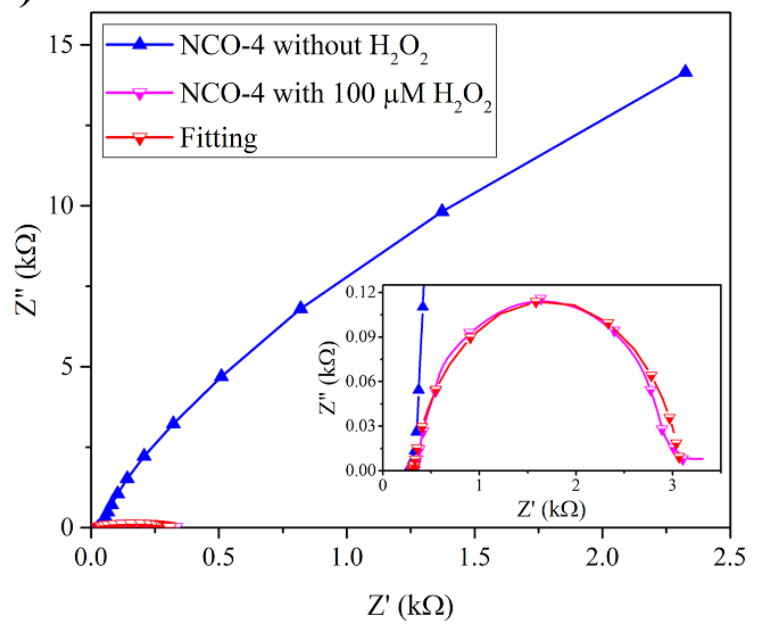

(c)

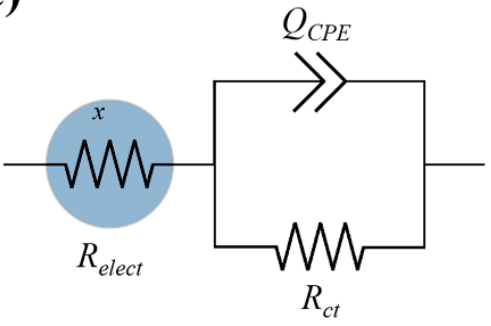

Figure 8 
(a)

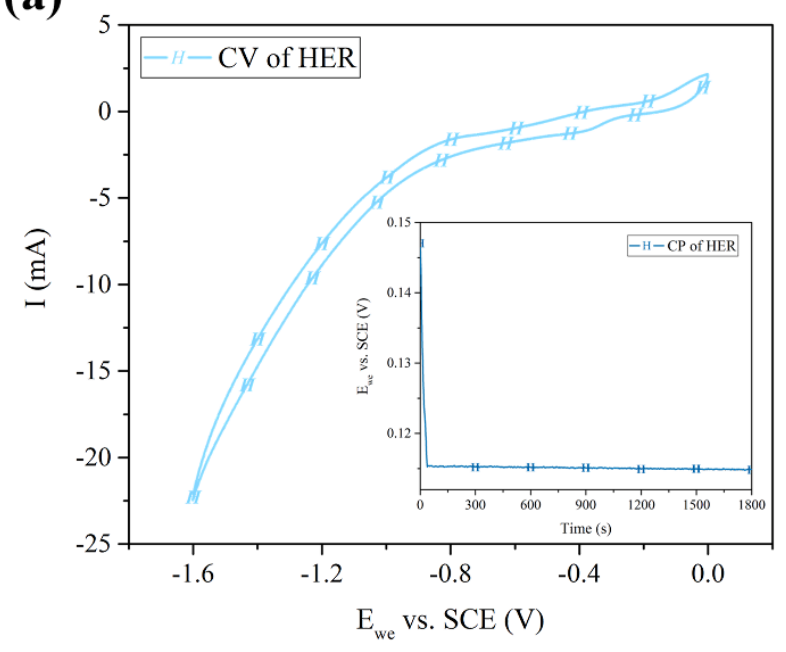

(c)

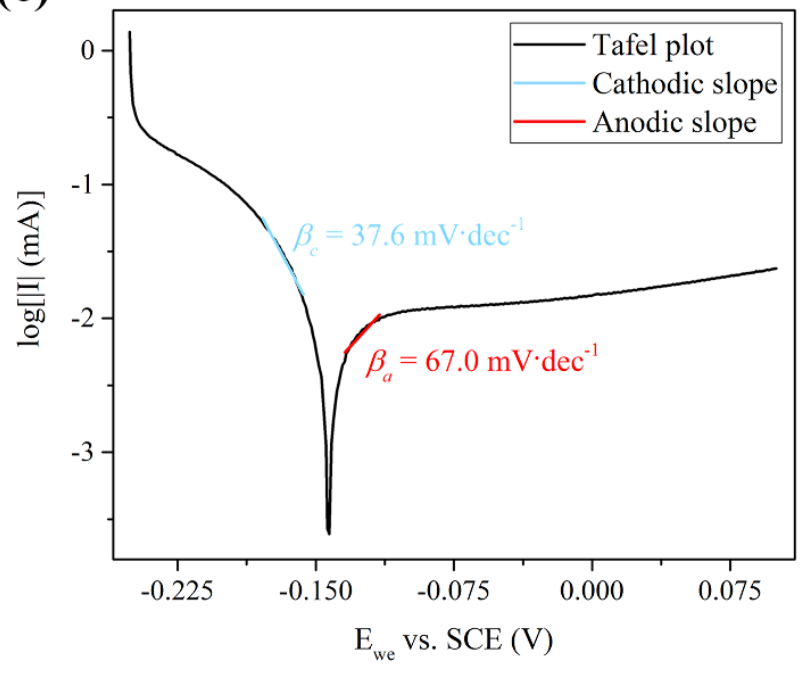

Figure 9

(b)

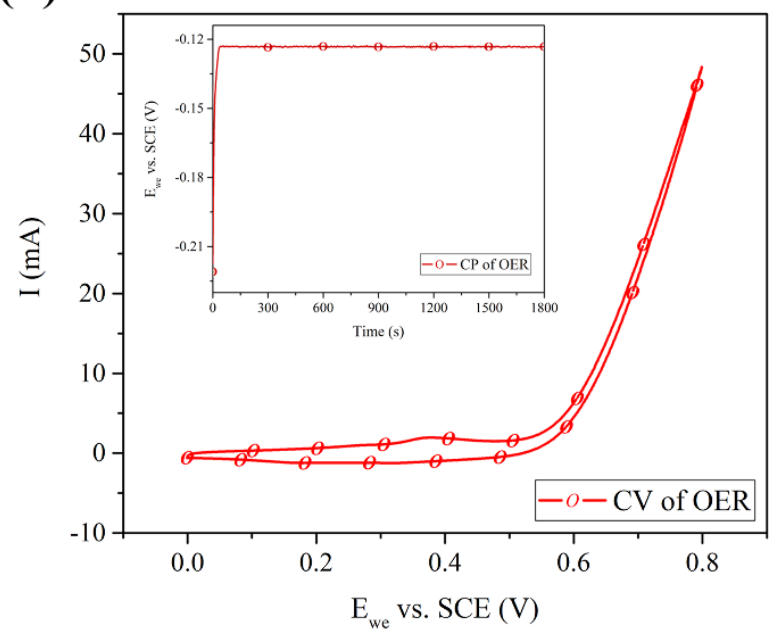

